\title{
Biocompatible propulsion for biomedical micro/nano robotics
}

DOI:

10.1016/j.bios.2019.111334

\section{Document Version}

Accepted author manuscript

Link to publication record in Manchester Research Explorer

\section{Citation for published version (APA):}

Halder, A., \& Sun, Y. (2019). Biocompatible propulsion for biomedical micro/nano robotics. Biosensors and Bioelectronics, 139, 111334. [111334]. https://doi.org/10.1016/j.bios.2019.111334

\section{Published in:}

Biosensors and Bioelectronics

\section{Citing this paper}

Please note that where the full-text provided on Manchester Research Explorer is the Author Accepted Manuscript or Proof version this may differ from the final Published version. If citing, it is advised that you check and use the publisher's definitive version.

\section{General rights}

Copyright and moral rights for the publications made accessible in the Research Explorer are retained by the authors and/or other copyright owners and it is a condition of accessing publications that users recognise and abide by the legal requirements associated with these rights.

\section{Takedown policy}

If you believe that this document breaches copyright please refer to the University of Manchester's Takedown Procedures [http://man.ac.uk/04Y6Bo] or contact uml.scholarlycommunications@manchester.ac.uk providing relevant details, so we can investigate your claim.

\section{OPEN ACCESS}




\section{Accepted Manuscript}

Biocompatible propulsion for biomedical micro/nano robotics

Arnab Halder, Yi Sun

PII: S0956-5663(19)30399-9

DOI: https://doi.org/10.1016/j.bios.2019.111334

Article Number: 111334

Reference: BIOS 111334

To appear in: Biosensors and Bioelectronics

Received Date: 27 February 2019

Revised Date: 11 May 2019

Accepted Date: 15 May 2019

Please cite this article as: Halder, A., Sun, Y., Biocompatible propulsion for biomedical micro/nano robotics, Biosensors and Bioelectronics (2019), doi: https://doi.org/10.1016/j.bios.2019.111334.

This is a PDF file of an unedited manuscript that has been accepted for publication. As a service to our customers we are providing this early version of the manuscript. The manuscript will undergo copyediting, typesetting, and review of the resulting proof before it is published in its final form. Please note that during the production process errors may be discovered which could affect the content, and all legal disclaimers that apply to the journal pertain. 


\title{
Biocompatible Propulsion for Biomedical Micro/Nano Robotics
}

\author{
Arnab Halder*, Yi Sun* \\ Department of Health Technology, Technical University of Denmark, \\ DK-2800 Kgs Lyngby, Denmark \\ *arhal@dtu.dk, \\ *suyi@dtu.dk
}

\begin{abstract}
:
Micro/Nano robots have shown enormous potential for diverse biomedical applications, such as targeted delivery, in vivo biosensing, minimally invasive surgery and cell manipulation through extending their area of operation to various previously inaccessible locations. The motion of these small-scale robots can be either self-propelled or remotely controlled by some external power sources. However, in order to use them for biomedical applications, optimization of biocompatible propulsion and precise controllability are highly desirable. In this article, the recent progresses about the biocompatible propulsion (e.g. self-propulsion, external stimuli based propulsion and bio-hybrid propulsion) techniques for these micro/nano robotic devices are summarized along with their applications, with a special focus on the advantages and disadvantages of different propulsion techniques. The current challenges and future perspectives of these small-scale devices are discussed in the final section.
\end{abstract}

\section{Introduction}

Micro/nano robots (MNR) are small-scale programmable machines, which can mimic the motion of natural microorganisms by converting diverse energy sources into their movement(Ornes, 2017). Synthetic MNRs have sizes ranging from tens of nanometers to several hundred micrometers(X. Z. Chen et al., 2018). Owing to their small-scale structures as well as propulsive nature, MNR systems are promising to access some previously inaccessible part of the human body parts and perform a specific action(Li et al., 2017b). Recent advancement of nanotechnology and materials science has led to the rapid progress of synthetic MNR systems(Yang et al., 2017) for diverse biomedical and environmental applications. These small-scale robots are often referred in the literature as micro/nanomotors(Gao and Wang, 2014), micro/nanoswimmers(T. Li et al., 2016), micro/nanoengines(Sanchez et al., 2011), micro/nanomachines(Wang and Pumera, 2018), micro/nanopropellers(Ghost and Fischer, 2009), micro/nanopumps(Wong et al., 2016) or micro/nanorockets(J. Li et al., 2016a) etc.

In 1959, Richard Feynman mentioned during his visionary talk "it would be interesting in surgery if you could swallow the surgeon(Feynman, 1992)." In 1966, American science fiction film 'Fantastic Voyage' presented a miniaturized submarine to clear the blood clot in patient's blood vessel. For the past several decades, numerous progresses have been made towards that target(Esteban-Fernández de Ávila et al., 2018). The Nobel Prize committee in Chemistry 
further acknowledged the importance of this research field in 2016 by awarding Sauvage, Stoddardt, and Feringa for the design and synthesis of molecular machines(Stoddart et al., 2016). With the advancement of micro/nanotechnology and smart materials, rapid progress of small-scale robotic devices has been achieved particularly over the last two decades(Yang et al., 2017). These MNR devices are particularly promising for revolutionize the healthcare sector by introducing novel theranostics capabilities(Kostarelos, 2010) such as in vivo biosensing, therapeutic delivery, microsurgery, detoxification etc.. The ideal biomedical MNR devices should have a physically adaptable structure with the patient's body, suitable load/unload capacity of functional entities (e.g. drugs, imaging agent, cells, nanoparticles etc.), precisely controlled propulsion, live tracking possibility through common medical imaging techniques and finally possibility of controlled degradation without leaving any toxic residues in patient's body(Sitti, 2018).

However, the community of MNR often faces significant challenges to find suitable strategies for the propulsion of these micro/nano robotic devices(Mallouk and Sen, 2009). The miniature version of traditional power sources is unavailable for the micro/nanoscale devices. Therefore, design and integration of non-toxic, biocompatible power/fuel sources for these tiny devices are very essential. Moreover, swimming of MNRs in biological media (e.g. blood) is often challenging due to presence of large concentration of ions(W. Hu et al., 2018). As the sizes of these small-scale devices go down to few micro/nanometer scales, the ratio of inertial forces to the surrounding medium viscous forces becomes very small(Yang et al., 2018). Therefore, the inertial forces for the motion of the micro/nanorobots become negligible. In the highly viscous, low Reynolds number medium, continuous power supply for the propulsion of these micro/nano devices are very important(Majumdar et al., 1972). Hence, combination of biocompatible as well as powerful engine with mico/nano robotic structure is highly desirable for their wide ranges of biomedical applications.

With the rapid progression in the field, a growing number of review articles are being published with focus on design and fabrication of wide ranges of MNR devices and for their applications(Campuzano et al., 2017; C. Chen et al., 2018b; Dey and Sen, 2017; Duan et al., 2015; Gao et al., 2018; Karshalev et al., 2018b; Kim et al., 2018; J. Li et al., 2016a; Li et al., 2017b; Medina-Sánchez et al., 2018; Safdar et al., 2018; Wang and Pumera, 2018). However, a specific review with particular focus on the biocompatible propulsion techniques of the MNR devices is still not available. In this report, we discuss the progress in the design and development of various biocompatible propulsion methods for MNR devices. The first part of this report will discuss about the self-propulsion methodologies, which will be mainly focused on chemical propulsion and enzyme-based propulsion techniques. The second part will discuss about different external stimuli-based propulsion techniques, such as magnetic, acoustic and light-based propulsion techniques. The third part will discuss about bio-hybrid propulsion techniques, which will be mainly focused on bacteria-based propulsion and eukaryotic cellbased propulsions. In the final section, we discuss the major challenges for the development of MNR devices, and present an outlook for the next generation MNR devices for biomedical applications. 


\section{Table 1}

\begin{tabular}{|c|c|c|c|c|}
\hline & & Key features & Advantages & Limitations \\
\hline \multirow{2}{*}{ 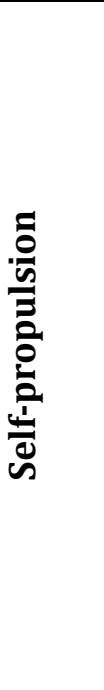 } & $\begin{array}{l}\text { Chemical } \\
\text { propulsion }\end{array}$ & $\begin{array}{l}\text { Bubbles are generated due to } \\
\text { chemical reactions with } \\
\text { surrounding liquid fuel, } \\
\text { expelled from the back of the } \\
\text { structure to propel the MNR. }\end{array}$ & $\begin{array}{l}\text { - } \text { High speed } \\
\text { - } \quad \text { Low cost } \\
\text { any special setup } \\
\text { for controlling the } \\
\text { motion. }\end{array}$ & $\begin{array}{l}\text { Most of the fuels } \\
\text { are toxic. } \\
\text { - Difficult for } \\
\text { continuous } \\
\text { supply of the fuel. } \\
\text { - Lack of } \\
\text { directional } \\
\text { motion. } \\
\text { - Short lifetime }\end{array}$ \\
\hline & $\begin{array}{c}\text { Enzyme } \\
\text { based } \\
\text { propulsion }\end{array}$ & $\begin{array}{l}\text { Surface immobilized } \\
\text { enzymes transfer the } \\
\text { chemical energy from a } \\
\text { catalytic reaction to cause } \\
\text { kinetic motion for the MNR. }\end{array}$ & $\begin{array}{l}\text { Biocompatibility of } \\
\text { the enzymes. } \\
\text { - Substrate } \\
\text { concentration } \\
\text { dependent motion. }\end{array}$ & $\begin{array}{ll}\text { Enzymes are } \\
\text { often unstable. } \\
\text { - } \quad \text { Lack of } \\
\text { directional } \\
\text { motion. } \\
\text { - } \quad \text { Low velocity. }\end{array}$ \\
\hline \multirow{3}{*}{ 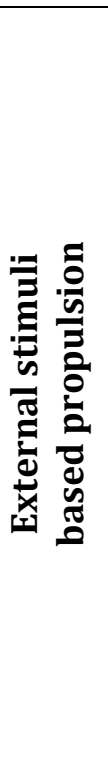 } & $\begin{array}{l}\text { Magnetic } \\
\text { propulsion }\end{array}$ & $\begin{array}{l}\text { Motion is controlled by } \\
\text { external magnetic source. }\end{array}$ & \multirow{3}{*}{$\begin{array}{ll}\text { - } & \text { Non-invasive. } \\
\text { - } & \text { Precise motion } \\
\text { - } & \text { control. } \\
\text { Biocompatible } \\
\text { propulsion } \\
\text { approach. } \\
\text { - Light is a } \\
\text { renewable energy } \\
\text { source. }\end{array}$} & \multirow{3}{*}{$\begin{array}{l}\text { Requirement for } \\
\text { special } \\
\text { experimental } \\
\text { setup to control } \\
\text { the motion. } \\
\text { Lack of } \\
\text { autonomous } \\
\text { motion. }\end{array}$} \\
\hline & $\begin{array}{l}\text { Acoustic } \\
\text { propulsion }\end{array}$ & $\begin{array}{l}\text { Motion is controlled by } \\
\text { external high-frequency } \\
\text { acoustic (or ultrasounds) } \\
\text { source. }\end{array}$ & & \\
\hline & $\begin{array}{l}\text { Light based } \\
\text { propulsion }\end{array}$ & $\begin{array}{l}\text { Motion is controlled by } \\
\text { external light source of } \\
\text { different wavelengths } \\
\text { (ultraviolet (UV) light ( } 10- \\
400 \mathrm{~nm} \text { ), visible light ( } 400- \\
700 \mathrm{~nm} \text { ), infrared light ( } 700 \\
\mathrm{~nm}-1 \mathrm{~mm}) \text { ). }\end{array}$ & & \\
\hline \multirow{2}{*}{ 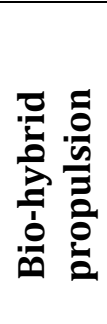 } & $\begin{array}{c}\text { Bacteria } \\
\text { based }\end{array}$ & \multirow{2}{*}{$\begin{array}{l}\text { Combination of different } \\
\text { propulsion technique by } \\
\text { harvesting energy from } \\
\text { different fuel sources. }\end{array}$} & \multirow{2}{*}{$\begin{array}{ll}\text { - } & \text { Biocompatible } \\
\text { propulsion } \\
\text { - } \\
\text { Good control for } \\
\text { directional control. } \\
\text { - } \\
\text { Muti-stimuli } \\
\text { responsive } \\
\text { approach. }\end{array}$} & \multirow{2}{*}{$\begin{array}{l}\text { Live cells are } \\
\text { often unstable } \\
\text { and difficult to } \\
\text { control under } \\
\text { certain } \\
\text { conditions. }\end{array}$} \\
\hline & $\begin{array}{l}\text { Eukaryotic } \\
\text { cell-based }\end{array}$ & & & \\
\hline
\end{tabular}

\section{Biocompatible propulsion techniques}

Various propulsion mechanisms have been developed to fuel the MNR devices to perform their operations. Based on their approaches, propulsion strategies are mainly categorized into three 
different types: self-propulsion, external stimuli based propulsion and bio-hybrid strategy. Table 1 showed a brief overview of different propulsion techniques and their specific advantages and disadvantages.

\subsection{Self-propulsion}

Self-propulsion approach is mainly based on local chemical reactions occurring on the surface of the MNR structure(Lin et al., 2016). Thus, the chemical energy is transformed to kinetic energy and generates locomotion for the MNRs. Self-propulsion strategy can be roughly classified into two categories, such as chemical propulsion, which usually requires various chemical fuels, and enzyme-based propulsion, which depends on the catalytic property of enzymes towards their substrates.

\subsubsection{Chemical propulsion}

Autonomous propulsion at micro/nanoscale represents one of the most desirable goals in MNR. Chemically powered and self-propelled particle-like micro/nanorobots are particularly interesting in this case due to their simple and tunable structure, cargo-loading capability and high-speed motion. Several transition metal-based catalytic nanoparticles are being used as catalysts to develop these kinds of small scale robots(Safdar et al., 2018). The first example of chemically powered self-propulsion was observed on a spherical micro particle half-coated with platinum (Pt) catalyst(Safdar et al., 2018). Their motion was generated when Pt catalyzes the decomposition of $\mathrm{H}_{2} \mathrm{O}_{2}$ and produces $\mathrm{O}_{2}$ bubbles $\left(2 \mathrm{H}_{2} \mathrm{O}_{2} \rightarrow 2 \mathrm{H}_{2} \mathrm{O}+\mathrm{O}_{2}\right)$. The motion was assessed under different $\mathrm{H}_{2} \mathrm{O}_{2}$ concentrations. The Janus particle showed directional motion and its velocity was proportional with the concentration of $\mathrm{H}_{2} \mathrm{O}_{2}$. Several other Pt catalystbased tubular micromotors are reported(Gao et al., 2012b, 2011; Khezri et al., 2019; B. Xu et al., 2018). Similarly, silver (Ag), nickel (Ni), iridium (Ir), ruthenium (Ru), manganese oxide $\left(\mathrm{MnO}_{\mathrm{x}}\right)$, titanium dioxide $\left(\mathrm{TiO}_{2}\right)$ based micro/nanorobots were also showed chemical propulsion in presence of $\mathrm{H}_{2} \mathrm{O}_{2}$ or hydrazine. However, these two solvents are considered as highly toxic for biological systems(Wang and Pumera, 2018). Therefore, biocompatible propulsion is not feasible for these cases. To address this limitation, alternative materials that could use biocompatible and nontoxic fuels are highly desirable.

Recently, a new class of inorganic catalytic nanoparticles have shown propulsion without using any toxic chemical fuels (Fig. 1A-D). For example, zinc (Zn) is widely used to produce hydrogen energy and it can produce hydrogen bubble upon hydration(Gao et al., 2015). (Fig. 1B, C, D left panel) Following this interesting property, Gao et al fabricated PANI/Zn based microtubular motors, which can propel in different acidic solutions (above 100 body lengths per second)(Gao et al., 2012c). One of the major advantages of using $\mathrm{Zn}$ is that it is safe as well as it can be electrodeposited in a simple manner. Another interesting example is magnesium $(\mathrm{Mg})$ based catalysts, which is low-cost, biocompatible and it can also evolve $\mathrm{H}_{2}$ by reducing water(C. Chen et al., 2018b). A hydroxide passivation layer normally covers the surface of Mg particles, which protects the Mg from reacting with water(Fournier-Bidoz et al., 2005). The dissolution 
of this passivation layer allows $\mathrm{Mg}$ to produce $\mathrm{H}_{2}$ bubbles and propel the corresponding particles (Fig. 1B, C, D middle panel). The Mg-based chemically propelled structures can cross few body lengths within a second(Mou et al., 2013). Similarly, aluminum (Al) can also reduce water and produce $\mathrm{H}_{2}$ bubbles. However, the formation of oxide passivation layer limits their application. To address these challenge, Gao et al combined Al with Ga to form an alloy structure(Gao et al., 2012a). Ga can help to penetrate the Al surface to remove the oxide layer. The as prepared Janus Ga-Al/Ti microparticles can achieve a speed up to $3 \mathrm{~mm} \mathrm{~s}^{-1}$ in water with a lifetime of over $5 \mathrm{~min}$. Precise reaction of calcium carbide $\left(\mathrm{CaC}_{2}\right)$ with water can produce acetylene gas, which can help to propel the $\mathrm{CaC}_{2}$ particles: $\left(\mathrm{CaC}_{2}+2 \mathrm{H}_{2} \mathrm{O} \rightarrow \mathrm{Ca}(\mathrm{OH})_{2}+\right.$ $\mathrm{C}_{2} \mathrm{H}_{2}$ ). A thin polymeric porous coating can help these particles to react with water in a controlled manner. Calcium carbonate-based particles are also very interesting to prepare MNRs drug delivery systems(Guix et al., 2016). Janus calcium carbonate-based MNRs showed autonomous motion at $\mathrm{pH} 6.5$, but with a relatively slow speed $\left(\approx 1.8 \mu \mathrm{m} \mathrm{s}^{-1}\right)$. Wang et al recently demonstrated that Zn and Mg-based MNRs can propel in the gastrointestinal tract (GI) tract and can be controlled to reach specific locations. They have demonstrated a magnesiumbased tubular MNR coated with an enteric polymer layer for delivering payload to a specific location (in GI tract) via dissolution of their coating layer(J. Li et al., 2016b)(Fig. 1B, C, D right panel). More interestingly, such MNRs were gradually dissolved in the GI fluids, without leaving any toxic residues behind. The efficiency of the acid and water-based propulsion helped the MNRs to associate with the stomach and intestine wall(De Ávila et al., 2017; Li et al., 2017a) (Fig. 1D). These acid-powered MNR propulsion can efficiently deplete protons and neutralize the gastric $\mathrm{pH}$. The chemically powered, body-fuel-propelled biocompatible and biodegradable MNRs are very promising for further in-vivo applications(Esteban-Fernández de Ávila et al., 2018). In a most recent work, the same group reported in vivo oral delivery of active Mg-based micromotor pills(Karshalev et al., 2018a). (Fig. 1E, F, G) The in vivo studies using a mouse model showed that the micromotor pill can efficiently shields and transports the active micromotors to the stomach for controlled release applications. A detailed overview of different inorganic nanoparticle based chemical propulsion can be found in a recent review by Safdar et al(Safdar et al., 2018).

Chemically propelled MNRs have achieved self-propulsion in mildly acidic medium in both in vitro and in vivo conditions. However, they are slow in speed and lack of precise positioning. Therefore, more in-depth and comprehensive studies are needed to further translate them for clinical applications.

\subsubsection{Enzyme-based propulsion}

Enzymes are ubiquitous biomolecule for all the living systems(Sengupta et al., 2013). They can use different biological fluids (i.e. available inside body) as fuels to generate motion(Sengupta et al., 2014). A surface immobilized enzyme can transfer the chemical energy from a catalytic reaction to kinetic motion, resulting in directional fluid pumping(Zhao et al., 2018). The enzyme bound surfaces can therefore act as chemically powered micro-engines. In presence of a substrate concentration gradient, active enzymes can move towards a higher substrate concentration region(Ma et al., 2016b). Therefore, properly combining selective enzyme 
molecules on a solid support or micro/nanorobot's body will help them to propel by utilizing different biological fluids as fuel. One of the possible mechanism behind this phenomenon is that enzymes generate sufficient mechanical energy through substrate binding and unbinding event(Zhao et al., 2018).

Enzymes are particularly interesting for biocompatible propulsion. Several different enzymes such as trypsin(Schattling et al., 2017), glucose oxidase (GOx)(Ma et al., 2015), GOx coupled with catalase(Abdelmohsen et al., 2016; Schattling et al., 2015), acetylcholinesterase (AChE), urease(Hortelão et al., 2018; Ma et al., 2016a, 2016c, 2015), and catalase(Dey et al., 2015; Ma et al., 2015; Ma and Sánchez, 2017; Sanchez et al., 2010) are being used as power engine for micro/nanorobots (Figure 2). In 2003, Mano and Heller were the first to combine enzymes with a carbon fiber (0.5-1 cm length and $7 \mu \mathrm{m}$ diameter), which was able to self-propel at the water-air interface(Mano and Heller, 2005). Later, Feringa and collaborators showed the autonomous propulsion of carbon nanotubes combined with glucose oxidase (GOx) and catalase(Pantarotto et al., 2008). Glucose oxidase is converting glucose into $\mathrm{H}_{2} \mathrm{O}_{2}$, and then catalase is reducing $\mathrm{H}_{2} \mathrm{O}_{2}$ into water and oxygen for its propulsion. The combination of glucose oxidase and catalase become very popular to biocatalytically power MNRs, which minimizes the unsuitability of using catalase for biological systems (due to the use of toxic $\mathrm{H}_{2} \mathrm{O}_{2}$ as fuel). Glucose oxidase is one of the most common enzymes, which is being used as microengine for a variety of MNRs(Zhang et al., 2014). Urease has also been widely used to power micro/nanorobots by the hydrolyzation of urea $\left(\mathrm{CO}\left(\mathrm{NH}_{2}\right)_{2}\right)$ into carbon dioxide $\left(\mathrm{CO}_{2}\right)$ and ammonia $\left(\mathrm{NH}_{3}\right)$. For example, Dey et al reported a biotin-streptavidin linkage based enzymes (urease and catalase) attached polystyrene beads, and their diffusion was measured by exposing them to different substrate concentrations(Dey et al., 2015). As evident from their studies, an enhanced diffusion was observed in the presence of the substrate, and the directional chemotaxis was happened in a substrate gradient. These studies also demonstrated that enzymes as microengine are capable enough to move units that are orders of magnitude bigger than the enzymes themselves. Acetylcholinesterase (AChE) has also been used as it can consume acetylcholine and generate motions(Patino et al., 2018). Sánchez et al studied different aspects of enzyme-powered Micro/Nanoswimmers such as different structures, materials, and enzymes varieties with special focus on their effect in motion dynamics(Ma et al., 2016a; Patiño et al., 2018). They further explored the effects of different sizes, fabrication methods and enzyme localization on their propulsion behavior(Goldberg et al., 1993). In a recent work, the same group demonstrated urease-powered MNRs for doxorubicin (Dox) anticancer drug loading, release, and efficient delivery to targeted cells. As a specific compound can simultaneously be product of a particular reaction as well as can be used as a substrate of another reaction, a new combined approach by using two or more enzymes are also being explored. However, the exact mechanism behind the enzyme based propulsion is still unclear(Illien et al., 2017). Recently, Sen et al derived a general expression for the active propulsion of an enzyme in its substrate's concentration gradient(Mohajerani et al., 2018). The derived general model involves three experimentally defined constants for quantifying chemotaxis, such as enzyme-substrate binding affinity $\left(\mathrm{K}_{\mathrm{d}}\right)$, Michaelis-Menten constant $\left(\mathrm{K}_{\mathrm{M}}\right)$, and level of diffusion enhancement in the associated substrate $(\alpha)$. A detailed overview of 
different enzyme based MNRs can be found in a recent review by Patiño et al(Patino et al., 2018).

Although enzymes based micro/nanorobots are very promising for various biomedical applications such as in vivo biosensing, drug delivery etc., an in-depth study is required to investigate detailed mechanism of how enzymes convert chemical energy to mechanical force, how conformation of enzyme will contribute to the motion as well as the dependence on the structure of enzyme-bound supports. Furthermore, precise positioning and directional motion based propulsion should be incorporated in order to use them for the diverse biomedical applications.

\subsection{External stimuli-based propulsion}

External stimuli-based propulsion techniques are more feasible to translate the MNR systems towards clinically relevant biomedical application area, where directional motion and precise positioning is more crucial. These techniques are mostly biocompatible due to their noninvasive nature. Diverse external stimuli-based energy sources are being used to generate propulsion such as magnetic fields, acoustic waves, light sources, electrical field etc.

\subsubsection{Magnetic propulsion}

Magnetic field-based propulsion is one of the most attractive motion for MNRs due to its possibility to operate remotely and wirelessly, guiding through directional motion as well as its minimal adverse effect while penetrating human body and tissues.

When a magnetic object with magnetic dipole momentum $\mathrm{m}$ (permanent or induced), is placed in a uniform external magnetic field (B), it does not experience any net magnetic force ( $F_{\text {mag }}$ $\nabla B)$ due to the zero field gradient $(\nabla B)$. However, the magnetic torque still can be present, which is represented as $\tau_{\mathrm{mag}}=\mathrm{m} \times \mathrm{B}$. Therefore, it can rotate the magnetic object until it aligns with the magnetic field. In order to propel a magnetic MNR, an inhomogeneous or a timevarying magnetic field should be applied. Furthermore, by carefully tuning the rotation axis of a magnetic field, MNRs can be steered in different directions.

Nelson's group from ETH Zurich are pioneers to develop the rotating magnetic field-based magnetic helical swimmers(Huang et al., 2015; Peters et al., 2014; Zhang et al., 2009) (Fig. 3AD). The motion of the helical magnetic swimmers is inspired by motion of bacteria, which are propelled by rotating their flagella. These micro robots have two parts: magnetic head and helical semiconductor tail. They were named as artificial bacterial flagellum (ABF). Later in another work, the same group used direct laser writing (DLW) to produce a new kind of ABF(Tottori et al., 2012). These ABF based MNRs have demonstrated great promise in cargo delivery for diverse in vitro and in vivo biomedical applications. The motion of ABF based MNRs are depends on magnitude and driving frequency of magnetic field.

Fischer's group fabricated another kind of helical magnetic micro robots with 1-2 $\mu \mathrm{m}$ length and 200-300 nm diameter(Schamel et al., 2014) (Fig.3 E-G). Those robots can swim in water with an average speed of $40 \mu \mathrm{m} \mathrm{s}^{-1}$. The same group designed and fabricated another helical 
magnetic micro robot with surface-immobilized urease(Walker et al., 2015). The micro robot can locally liquefy and propel through gastric mucin gels in presence of rotating magnetic fields. The immobilized urease enzyme can increase the $\mathrm{pH}$ value and convert the highly viscous mucus into liquid. This work exhibits biomimicking surface modification of MNRs for target-specific drug delivery.

Hoop et al reported a chitosan hydrogel-based magnetic MNRs for controlled drug delivery applications(Hoop et al., 2016). The hydrogel-based surface is insoluble in neutral pH, but at a weakly $\mathrm{pH}$ condition it starts swelling and slowly releases the drug. The MNRs are fabricated by electrodepositing Ni nanotubes on polycarbonate (PC) membrane-based sacrificial template with $2 \mu \mathrm{m}$ average pore diameter. The nanotubes are $6 \mu \mathrm{m}$ in length and with a wall thickness of $200 \mathrm{~nm}$. Later, the chitosan hydrogel mixed with the model drug was filled on the nanotube surface. Moreover, another layer of gold thin film was coated onto it to load a secondary drug or a fluorescence trace molecule. The motion of the composite MNRs was manipulated by a rotating magnetic field. When the surrounding $\mathrm{pH}$ was changed from 7.4 to 6 , the drug release rate was increased by 2.5 folds. Pané et al introduced a new kind of triggering mechanism for controlled drug release from MNRs by using magnetoelectric effect(Chen et al., 2017). They have fabricated a core-shell hybrid nanowire by consecutive electrodeposition of poly(vinylidene fluoride-trifluoroethlyene) nanotube shell and $\mathrm{Fe}_{80} \mathrm{Ga}_{20}$ alloy nanorod core. The shell part consists of piezoelectric materials and the core part has high magnetostrictive coefficient. Under influence of an external magnetic field, the magnetostrictive core part deforms and transmits the mechanical strain to the outer shell. Thus, the electric polarization of the piezoelectric polymer shell changes and their surface charges are also reordered. As a result, the loaded drug can be released at the targeted area. Yan et al recently reported a helical, multifunctional biohybrid magnetite MNR for imaging-guided therapy(Yan et al., 2017) (Fig. $3 \mathrm{H}, \mathrm{I}$ ). The helical MNRs were fabricated from Spirulina microalgae through dip-coating process in magnetite $\left(\mathrm{Fe}_{3} \mathrm{O}_{4}\right)$ suspensions. The inherent fluorescence property of the microalgae permitted in vivo imaging and remote diagnostic sensing without any further surface modifications. Moreover, the MNRs are capable for autonomous degradation and displayed selective cytotoxicity to cancer cell lines. Bozuyuk et al recently reported a magnetically powered and external light stimulated double-helical MNRs (6 $\mu$ m diameter X 20 $\mu \mathrm{m}$ length) for on-demand actively release of chemotherapeutic drug. Within $204 \mathrm{~h}$ and physiologically relevant conditions, the MNRs can degrade into nontoxic products(Bozuyuk et al., 2018) (Fig. 4A-D). A detailed overview of magnetically propelled MNRs can be found in a recent review by Chen et al(X. Z. Chen et al., 2018).

The magnetic MNRs are very promising real-world biomedical areas, whereas magnetic fieldbased propulsion only works for the magnetic materials, which restricts their wide applicability. A suitable combination of biocompatible materials coated magnetic nanostructures with the assembly of MNRs can address this challenge.

\subsubsection{Acoustic propulsion}


Acoustic (or ultrasound) has been routinely used in diverse biomedical applications for long time.(Mitragotri, 2005) Acoustics (or ultrasounds) are sound waves with a higher frequency than the normal human upper audible limit. In recent years, considerable attention has been paid to the use of acoustic field-based propulsion for MNR devices in biofluids(Li et al., 2017b). Due to their large propulsion force and excellent biocompatibility, acoustic field-based propulsion are becoming popular for biomedical MNRs.

Huang et al reported that cells, microorganisms could be manipulated by standing surface acoustic wave generated by pressure fields(Ding et al., 2012). They referred them as acoustic tweezers. Fischer et al recently demonstrated a holographic technique for the acoustic manipulation(Melde et al., 2016). It can convert a planar wavefront from the transducer to a designed phase gradient. Wang et al from UCSD reported an ultrasound (US) triggered and bubble propelled rolled up micro robotic tubes(Kagan et al., 2012). The micro robotic tubes with perfluorocarbon (PFC) particles attached to the inner side can be propelled by US irradiation. The bubbles are formed by the acoustic vaporization of the PFC particles. The average speed of micro robotic tubes was $6 \mathrm{~m} \mathrm{~s}^{-1}$ and it was successful to penetrate into lamb kidney tissues. In another work, the same group reported a new type of acoustic nanomotors with an asymmetric structure(Garcia-Gradilla et al., 2013). One end of this multi-segment nanowire is modified for generating local pressure gradient. In presence of acoustic pressure, the MNR is propelled from the modified end. The new type of MNR can participate in targeted delivery of cargoes, drugs and bacteria. Ultrasonically propelled drug-loaded MNRs demonstrated 30 folds more efficiency in bacteria killing comparing to the static ones. This is due to their active motion in sample surroundings. In a recent work, the same group reported a new type of ultrasonically propelled MNRs for glucose responsive insulin delivery application(Díez et al., 2017). In this case, a glucose responsive phenylboronic acid functionalized glucose oxidase was combined with an insulin loaded mesoporous silica integrated gold nanowires (Fig. 4E-G).

Although these ultrasonically propelled MNRs have shown great promises various applications, they can be difficult to use in in vivo conditions as the predictable standing wave field can be challenging to establish inside human body. Nelson's group from ETH reported a new kind of MNR, which can be propelled in travelling acoustic waves(Ahmed et al., 2016). These waves can interact directly with the swimmer's body and they are independent of the acoustic field generated in the chamber. The MNRs were fabricate by multistep electrodeposition. The tail part of these MNRs are consist of polypyrrole based artificial flagellum and the head part contains metal. In presence of US, flagellum-based tail undergoes oscillations and generates a steady flow field on the surrounding media. Ultrasonically propelled MNRs are also efficient for cellular internalization and intracellular delivery of biochemical cargoes. Recently, Mallouk et al reported a new type of acoustic MNRs based intercellular propulsion(Wang et al., 2014). The MNRs are covered with HeLa cells via phagocytosis. Chen et al reported a new type of acoustic MNRs for intracellular gene-silencing strategy(Esteban-Fernández De Ávila et al., 2016). Recently, Ávila et al reported an ultrasound-propelled biomimetic MNRs comprising of gold nanowires coated with a hybrid of dual cell membrane from red blood cell (RBC) and platelet (PL)(De Ávila et al., 2018). The functionalized MNRs is capable of eliminating different biological threat agents such as pathogenic bacteria and toxins. 
Even though acoustic-based MNRs are very advantageous in various bio-applications, additional in-depth study is required to determine their propulsion mechanism and to assess applicability in in vivo conditions.

\subsubsection{Light based propulsion}

Light is one of the most preferable alternative power source for the actuation of MNRs. Due to their possibility to reduce the beam size to sub-micrometer scales and the availability of wide ranges of wavelengths (ultraviolet (UV) light (10-400 nm), visible light (400-700 $\mathrm{nm}$ ), infrared light (700 nm-1 mm).), it becomes a valuable renewable energy source to power the MNRs(J. Wang et al., 2018).

UV light driven Janus MNRs are comprehensively studied due to their ionizing radiation associated highly reactive chemical processes(Xu et al., 2017). The first reported light induced MNRs were self-diffusiophoresis associated asymmetric photodecomposition of AgCl particles in deionized (DI) water(Ibele et al., 2009). Those particles had demonstrated an interesting cooperative behavior. $\mathrm{TiO}_{2}$ is another special kind of catalyst, which can produce highly oxidative radicals during $\mathrm{UV}$ exposures. $\mathrm{TiO}_{2}$ particles also exhibited UV-induced autonomous motion related to a diffusiophoresis mechanism(Hong et al., 2010). At low UV light intensity, Janus $\mathrm{TiO}_{2}$-Au particles can autonomously propel by a self-electrophoresis mechanism. In addition, integration of a paramagnetic nickel layer permitted their directional magnetic field based control. Furthermore, an on/off control is possible in presence and absence of UV light source. The MNRs exhibited a direct correlation between their speed and UV light irradiation(Dong et al., 2016). In another example, anatase Ti02/Pt Janus particles demonstrated photocatalytic water splitting in presence of UV light, which is very promising for organic pollutant degradation(Mou et al., 2016). To maximize the degradation efficiency, pulsed mode UV light was used. Similarly, another Janus carbon tungsten trioxide with a gold layer (Au-WO3@C particles) based nanostructures were reported for the fast decomposition of toxic pollutants Rhodamine B in presence of UV light(Zhang et al., 2017). Recently, Bozuyuk et al reported a $365 \mathrm{~nm}$ UV light triggered drug release from a 3D printed biocompatible and biodegradable magnetic biopolymer composite based MNRs. The MNR also showed controlled storability under $10 \mathrm{mT}$ rotating magnetic field. The chemotherapeutic drug release activity of the MNR was tested under physiological condition. The MNR was degraded within $204 \mathrm{~h}$ without leaving any toxic degradation product.

Visible light-based propulsion is another most popular technique as their wide availability in everywhere around us. Volpe et al reported a propulsion by Au-capped silica particles in a critical binary liquid mixture and in presence of light (532 nm)(Volpe et al., 2011). In other works, hematite encapsulated polymer micro/nanoparticles participate in $\mathrm{H}_{2} \mathrm{O}_{2}$ decomposition in presence of visible light(Polin et al., 2009). Photocatalytic metal oxide incorporated Janus copper (I) oxide - Au microparticles showed self-propulsion behavior in presence of $\mathrm{H}_{2} \mathrm{O}_{2}$ and visible light through self-electrophoresis(Zhou et al., 2017). In another work, bismuth oxyiodide (BiOI)-based Janus microparticles showed similar behavior in presence of 
water(Dong et al., 2017). In presence of UV and visible light, black TiO2 particles half-covered with $\mathrm{Au}$ showed an excellent propulsion in both of $\mathrm{H}_{2} \mathrm{O}_{2}$ and in pure water(Dong et al., 2017). Due to their nondestructive and noninvasive nature, near IR light (NIR) sources (780-2500 $\mathrm{nm}$ ) became very popular for wide ranges of biological applications(Safdar et al., 2017). It has a penetration range of penetration range of 1-3 $\mathrm{mm}$. Jiang et al reported for first time about the movement of Janus MNRs in presence of IR light(Jiang et al., 2010). They had prepared a silica microparticle combined with gold, which can absorb IR light at a local temperature gradient. $\mathrm{Wu}$ et al introduced an on/off switchable motion of MNRs in presence of $\mathrm{H}_{2} \mathrm{O}_{2}$ and NIR light(Y. Wu et al., 2015). When the same MNR was converted to Janus structure with thin gold layer, it exhibited autonomous propulsion in water medium. The motion was dependent on light intensity. The Janus MNR also showed directional motion in presence of HeLa cells, which was due to electrostatic interaction positively charged Janus structure and negatively charged HeLa cell membrane(Y. Wu et al., 2016).

As the size of the light beam can be reduced to sub-micrometer by using some precise optical devices, light can a good alternative power source for the propulsion of MNR devices. Moreover, the recent popularity of renewable energy sources is making light a very promising energy source for the MNRs.

\subsection{Bio-hybrid propulsion}

Combination of different propulsion techniques by harvesting energy from different fuel sources offers new possibility for the motion of MNRs. This combined approach of propulsion can contribute not only for the motion but also for achieving specific tasks such as triggered release of therapeutics. There is growing interests to combe microbes and cells to MNRs due to their intrinsic biocompatibility. Bio-hybrid propulsion can be generally classified into two different categories: bacteria-based and eukaryotic cell-based MNRs.

\subsubsection{Bacteria-based propulsion}

By converting chemical energy into mechanical motion, bacteria can swim in their surrounding microenvironment and maintain their direction in response to different environmental gradients. Bacterial cells are long being used for medical therapeutic applications. For example, Serratia marcescens, a flagellated gram-negative bacterium was first used (2004) for the drug delivery application at the micron scale. The invasive property of Listeria monocytogenes was used to deliver nanoparticles and nucleic acid-based model drugs into both in vitro and in vivo conditions. Fernandes et al(Fernandes et al., 2011) attached a motile bacteria (Escherichia coli) to a submicron-scale cargo immobilized on a modified gold patterns using surface modification strategy and bacteria-cargo conjugates can be released on demand. They have demonstrated that the bacteria can be used to propel the cargo at sub micrometer scale. In another example, magnetotactic bacterial species (Magnetococcus sp. (MC-1)) are used to penetrate into an ex vivo solid tumor through external magnetic guidance(Felfoul et al., 2011). Recently, Stanton et al(Stanton et al., 2017a) demonstrated a single E. coli bacteria entrapped electropolymerized 
polypyrrole (Ppy) microtube based MNRs. The MNRs has a bacteria-attractant polydopamine inner layer and an additional layer of electroplated Ni for magnetic guidance. In another work, the same group reported E. coli bacteria combined Janus metallic/ polystyrene (PS) MNRs with (DOX) as cargo(Moore et al., 2013). An additional Fe cap was associated with structure to control the directional motion of the MNR structure. Martel et al recently introduced a new strategy for preparing drug-containing nanoliposome combined magnetotactic bacteria Magnetococcus marinus strain MC-1 through covalent binding(Felfoul et al., 2016). These bacteria contain a chain of magnetic nanocrystals for further controlling them through local magnetic field. Due to the magnetotaxis and anaerobicity of the bacteria, the overall platform was successful for targeted drug delivery to tumor hypoxic regions. Similarly, another magnetotactic bacteria Magnetosopirrillum gryphiswalense (MSR-1) were combined with cargo-loaded mesoporous silica microtubes to build hybrid MNRs(Stanton et al., 2017b). These hybrid devices had demonstrated their capability of antibiotic delivery to an infectious biofilm. Metin Sitti's group from MPI-IS have recently introduced a diverse variety of bacteria based MNRs(Hosseinidoust et al., 2016; Park et al., 2017). Mostaghaci et al. reported bacteria-based bio-adhesive MNR design through mannose-lectin interaction for urinary and gastrointestinal delivery of therapeutics(Mostaghaci et al., 2017). Park et al reported a versatile bacteria-based MNR, which possess chemotactic motion, magnetic control, and enhanced drug-delivery capabilities. Singh et al. fabricated a bacteria powered MNR through a facile surface patterning technique(Singh and Sitti, 2016). They had attached the E. coli to the MNR structure via biotinstreptavidin interaction. In another work(Singh et al., 2017), they have fabricated new kind of bacterial MNR by using streptavidin-functionalized double-micelle microemulsions and E. coli MG1655. The proposed bacteria-driven MNRs demonstrated the possibility of further development of a next generation soft, biocompatible bio-carriers. In another recent work, Alapan et al. demonstrated a novel fabrication strategy of bacterial powered MNRs using RBCs as cargo transporters and the motile bacteria (E. coli MG1655) as actuators(Alapan et al., 2018a) (Fig. 5A-F). Autonomous and on-board propulsion of bio-hybrid MNRs was powered by bacteria, and their magnetic guidance based directional motion was enabled by SPIONs loaded into the RBCs. The MNRs can release the loaded DOX at different $\mathrm{pH}$ conditions, and active deformation of the cargo unit with the bacteria's own propulsive force through narrow channels was revealed for the first time in literature. Moreover, an on-demand light-activated hyperthermia termination switch was engineered to the MNRs to kill them after their operation. In their previous work, the same group demonstrated a single Escherichia coli bacterium functionalized drug-loaded polyelectrolyte multilayer (PEM) MNRs with embedded magnetic nanoparticles. The resulting MNRs can swim directionally at a mean speeds of up to $22.5 \mu \mathrm{m} / \mathrm{s}$ and deliver anticancer drugs to targeted location(Park et al., 2017)(Fig. 5G-I). Recently, the same group reported a unicellular freshwater green microalga (Chlamydomonas reinhardtii) powered biocompatible and biohybrid MNR(Yasa et al., 2018)(Fig. 5J-L). The surface of the microalgae was functionalized with magnetic spherical cargoes $(1 \mu \mathrm{m}$ in diameter) through noncovalent interactions. The bio-hybrid algal MNRs demonstrated a proofof-concept active cargo delivery.

\subsubsection{Eukaryotic cell-based propulsion}


Eukaryotic cell-based MNRs provides the opportunity to engineer the patient's own cells for the fabrication of next generation theranostic MNRs(Esteban-Fernández De Ávila et al., 2018). These cell-based entities can be ideal for diverse small-scale biomedical robotic device development due to their intrinsic biocompatibility, wide availability inside body, easy clearance possibility and further capability of loading drugs into them. Red Blood Cells (RBC) and sperm cells are two most common examples for this case.

RBCs are one of the most abundant type of blood cells. Due to their biocompatibility, low immunogenicity, flexible nature and long circulation time, RBCs are becoming very popular for diverse bio-carrier applications(Han et al., 2018). Wang's group has demonstrated that RBCs can be loaded with drugs as well as with superparamagnetic nanoparticles by a hypotonic dilution method. The MNR can be propelled with ultrasound waves as well as steered with external magnetic fields(Wu et al., 2014; Z. Wu et al., 2015). The modified RBC-based MNRs demonstrated good biocompatibility comparable to their native counterparts. In another work, the same group showed red blood cell (RBC) membranes and platelet (PL) membranes functionalized gold nanowire MNR for multipurpose removal of biological threat agents(De Ávila et al., 2018) (Fig.6A-F). The biomimetic MNR demonstrated rapid and efficient propulsion in whole blood without any apparent biofouling (Fig.6G-I). Despite numerous advantages, several challenges should be addressed in order to clinically translate them. During different conjugation process with the RBCs, their outer cell membrane must be carefully preserved. Moreover, the biological barrier crossing ability of the RBC based MNRs must be improved.

Due to the special swimming ability in the female reproductive system, sperm cells have some unique advantages for the treatment of different gynecologic problems and cervical cancer(H. $\mathrm{Xu}$ et al., 2018). Moreover, they can be loaded with hydrophilic drugs and exhibit controlled release profile due to their compact structure(Makhluf et al., 2008). Schmidt's group is pioneering for the development of sperm based MNRs. In their recent review(Magdanz et al., 2017), they have discussed about the fabrication of single spermatozoa-based bio-hybrid MNRs. These special kind of MNRs are named as spermbots, which are very promising for the in vitro fertilization applications(Medina-Sánchez et al., 2016)(Fig. 6J, K). Magnetic materials were further combined with the spermbot structure to increase their motion controllability. However, in spite of their many advantages, further in-depth study on their precision motion and cargo transporting abilities are needed for their future clinical applications. A detailed overview of bio-hybrid propulsion based MNRs can be found in the recent review by Ávila et al(Esteban-Fernández De Ávila et al., 2018) and Alapan et al(Alapan et al., 2018b).

Bio-hybrid based propulsion for MNR devices provide an efficient platform by combing the artificial structures and living bio-organisms(Schuerle et al., 2019). Several challenges are needed to be addressed in order to translate these integrated devices for real world applications. The bio-organisms often show low structural flexibility and poor lifetime during their applications. Moreover, the loss of their free swimming speed and lack of proper coupling methods with artificial micro/nano structures often possess a significant drawback for their applications. Addressing these issues can prepare the bio-hybrid MNR devices for diverse biomedical applications.

\section{Conclusion and outlook}


Despite enormous progress made in MNR devices in the last two decades, the real time clinical usability of these small-scale devices are still in infancy. For most of the cases, the activity of these MNRs are limited only to biomimetic entities, cell culture dishes, ex vivo cells and tissues, or small animal models(Yang et al., 2018). There are still several significant challenges to be addressed in order to translate these small-scale devices for real world applications

i. A majority of the currently available MNR devices mimic the structure of their naturally available counterparts(Z. Wu et al., 2016). However, due to the lack of flexibility in their structure, they are not particularly suitable of in vivo biomedical applications. These MNR devices can damage the internal tissues and cause inflammation. Use of physically intelligent materials for the construction of soft robotic structures should be considered for prevention of these issues(C. Hu et al., 2018). A soft, elastic structure with physical adaption property can provide an ideal solution for this case(Sitti, 2018). Bio-responsive soft polymer hydrogel-based materials can be particularly interesting for their construction. Polymer hydrogels are three dimensional, swollen cross-linked polymer networks. Due to their highly tunable material structure, biocompatibility, stimuliresponsive nature and possibility for precise 3D printing, they are being used widely for diverse biomedical applications. Moreover, the polymer hydrogel-based structure can stably accommodate therapeutic drugs and ensure their controlled release.

ii. Combination of novel biocompatible and functional nanomaterials with MNR structure can open up a new generation of MNR devices(Halder et al., 2017, 2016). Twodimensional layered nanomaterials are currently being considered as most promising materials for the next generation biomedical devices(Cao et al., 2018; Choi et al., 2019). Due to their excellent physicochemical properties, these 2D materials can be ideal candidate for the construction of the next-generation multifunctional MNR structure.

iii. The MNR device structure must allow simple and controllable loading and unloading of the desired cargos such as drugs, cells, biomaterials and other possible micro/nano particles at the targeted locations(Esteban-Fernández de Ávila et al., 2018). Moreover, their biocompatible propulsion can be used to cross different biological barriers and to deliver therapeutics to targeted location.

iv. An important challenge for these MNR devices is to find new, suitable, biocompatible and autonomous energy sources to fuel them for their operations at micro/nanoscale. The currently present self-propelled MNRs are mostly relied on toxic fuels and water. The water based propulsions are often suffer from short lifetime(C. Chen et al., 2018b). External stimuli-based propulsion can solve these challenges. However, they create a barrier for autonomous propulsion. A combinational approach such as bio-hybrid propulsion can be exciting for this case(Chen et al., 2019; Ren et al., 2018).

v. Real world clinical application of micro/nanorobotics devices need real time tracking inside the patient's body(J. Li et al., 2016a). However, tracking at micro/nano scale is often challenging. Therefore, currently available medical imaging techniques such as Magnetic resonance imaging (MRI), positron emission tomography (PET), computerassisted x-ray tomography (CAT), ultrasound imaging, etc. should be made compatible with the micro/nanorobotics structure(Vartholomeos et al., 2011; Vilela et al., 2018; Yan 
et al., 2017). Suitable incorporation of biocompatible nanomaterials and fluorescent quantum dots(Halder et al., 2018) can offer a solution in this case.

vi. Often, a single MNR device is unable to finish a particular task. Therefore, establishment of collective behavior and communication between the MNRs can be helpful to perform a specific operation(C. Chen et al., 2018a).

vii. The overall safety profile of the therapeutic MNRs should be considered carefully. Ideally, the MNR structures should have controlled biodegradability, which should destroy itself after performing its assigned task in a controllable manner and maintain a low waste profile inside the body(Z. Wu et al., 2016). Most of the recently reported biodegradable MNR systems are only tested in in vitro condition(Bozuyuk et al., 2018; X. Wang et al., 2018). Investigation of their in vivo biocompatibility profile is vital for their translation to real world biomedical applications. Furthermore, the MNR devices must be sterile before using them for in vivo biomedical applications.

viii. Consistency in structure as well as their functionality is another important aspect for the performance of the MNR devices. Therefore, repeatability and reproducibility in manufacture and assays for the each MNR should be carefully optimized.

ix. Finally, the integration of complex functionality on a single standalone structure could be very promising for the next generation MNR devices. The ideal MNR devices should be a combination of biocompatible materials, adaptable structures, precise propulsion controllability, low toxicity, minimal potential immunogenic responses as well as the controlled biodegradability inside the body.

We envision that a close collaboration between the researchers from materials science, nanoengineering, robotics, biology, machine learning and clinicians would be able to solve these challenges and expand the horizon of MNR devices for real world applications.

\section{Acknowledgement}

This work is supported by Villum Fonden Denmark, Project no. 13153.

\section{References}

Abdelmohsen, L.K.E.A., Nijemeisland, M., Pawar, G.M., Janssen, G.J.A., Nolte, R.J.M., Van Hest, J.C.M., Wilson, D.A., 2016. Dynamic Loading and Unloading of Proteins in Polymeric Stomatocytes: Formation of an Enzyme-Loaded Supramolecular Nanomotor. ACS Nano 10, 2652-2660. https://doi.org/10.1021/acsnano.5b07689

Ahmed, D., Baasch, T., Jang, B., Pane, S., Dual, J., Nelson, B.J., 2016. Artificial Swimmers Propelled by Acoustically Activated Flagella. Nano Lett. 16, 4968-4974. https://doi.org/10.1021/acs.nanolett.6b01601

Alapan, Y., Yasa, O., Schauer, O., Giltinan, J., Tabak, A.F., Sourjik, V., Sitti, M., 2018a. Soft erythrocyte-based bacterial microswimmers for cargo delivery. Sci. Robot. 3, eaar4423. https://doi.org/10.1126/scirobotics.aar4423

Alapan, Y., Yasa, O., Yigit, B., Yasa, I.C., Erkoc, P., Sitti, M., 2018b. Microrobotics and Microorganisms: Biohybrid Autonomous Cellular Robots. Annu. Rev. Control. Robot. Auton. Syst. 2, annurev-control-053018-023803. https://doi.org/10.1146/annurev- 
control-053018-023803

Bozuyuk, U., Yasa, O., Yasa, I.C., Ceylan, H., Kizilel, S., Sitti, M., 2018. Light-Triggered Drug Release from 3D-Printed Magnetic Chitosan Microswimmers. ACS Nano 12, 9617-9625. https://doi.org/10.1021/acsnano.8b05997

Campuzano, S., Esteban-Fernández De Ávila, B., Yáñez-Sedeño, P., Pingarrón, J.M., Wang, J., 2017. Nano/microvehicles for efficient delivery and (bio)sensing at the cellular level. Chem. Sci. 8, 6750-6763. https://doi.org/10.1039/c7sc02434g

Cao, X., Halder, A., Tang, Y., Hou, C., Wang, H., Duus, J.Ø., Chi, Q., 2018. Engineering twodimensional layered nanomaterials for wearable biomedical sensors and power devices. Mater. Chem. Front. 2, 1944-1986. https://doi.org/10.1039/C8QM00356D

Chen, C., Chang, X., Teymourian, H., Ramírez-Herrera, D.E., Esteban-Fernández de Ávila, B., Lu, X., Li, J., He, S., Fang, C., Liang, Y., Mou, F., Guan, J., Wang, J., 2018a. Bioinspired Chemical Communication between Synthetic Nanomotors. Angew. Chemie - Int. Ed. 57, 241-245. https://doi.org/10.1002/anie.201710376

Chen, C., Karshalev, E., Guan, J., Wang, J., 2018b. Magnesium-Based Micromotors: WaterPowered Propulsion, Multifunctionality, and Biomedical and Environmental Applications. Small 14, 1-10. https://doi.org/10.1002/smll.201704252

Chen, C., Soto, F., Karshalev, E., Li, J., Wang, J., 2019. Hybrid Nanovehicles: One Machine, Two Engines. Adv. Funct. Mater. 29, 1806290. https://doi.org/10.1002/adfm.201806290

Chen, X.-Z., Hoop, M., Shamsudhin, N., Huang, T., Özkale, B., Li, Q., Siringil, E., Mushtaq, F., Di Tizio, L., Nelson, B.J., Pané, S., 2017. Hybrid Magnetoelectric Nanowires for Nanorobotic Applications: Fabrication, Magnetoelectric Coupling, and Magnetically Assisted In Vitro Targeted Drug Delivery. Adv. Mater. 29, 1605458. https://doi.org/10.1002/adma.201605458

Chen, X.Z., Jang, B., Ahmed, D., Hu, C., De Marco, C., Hoop, M., Mushtaq, F., Nelson, B.J., Pané, S., 2018. Small-Scale Machines Driven by External Power Sources. Adv. Mater. 30, 1705061. https://doi.org/10.1002/adma.201705061

Choi, C., Lee, Y., Cho, K.W., Koo, J.H., Kim, D.-H., 2019. Wearable and Implantable Soft Bioelectronics Using Two-Dimensional Materials. Acc. Chem. Res. 52, 73-81. https://doi.org/10.1021/acs.accounts.8b00491

De Ávila, B.E.F., Angsantikul, P., Li, J., Angel Lopez-Ramirez, M., Ramírez-Herrera, D.E., Thamphiwatana, S., Chen, C., Delezuk, J., Samakapiruk, R., Ramez, V., Zhang, L., Wang, J., 2017. Micromotor-enabled active drug delivery for in vivo treatment of stomach infection. Nat. Commun. 8. https://doi.org/10.1038/s41467-017-00309-w

De Ávila, B.E.F., Angsantikul, P., Ramírez-Herrera, D.E., Soto, F., Teymourian, H., Dehaini, D., Chen, Y., Zhang, L., Wang, J., 2018. Hybrid biomembrane-functionalized nanorobots for concurrent removal of pathogenic bacteria and toxins. Sci. Robot. 3, eaat0485. https://doi.org/10.1126/scirobotics.aat0485

Dey, K.K., Sen, A., 2017. Chemically Propelled Molecules and Machines. J. Am. Chem. Soc. 139, 7666-7676. https://doi.org/10.1021/jacs.7b02347

Dey, K.K., Zhao, X., Tansi, B.M., Méndez-Ortiz, W.J., Córdova-Figueroa, U.M., Golestanian, R., Sen, A., 2015. Micromotors Powered by Enzyme Catalysis. Nano Lett. 15, 8311-8315. https://doi.org/10.1021/acs.nanolett.5b03935

Díez, P., Esteban-Fernández De Ávila, B., Ramírez-Herrera, D.E., Villalonga, R., Wang, J., 2017. Biomedical nanomotors: Efficient glucose-mediated insulin release. Nanoscale 9, $14307-$ 14311. https://doi.org/10.1039/c7nr05535h

Ding, X., Lin, S.-C.S., Kiraly, B., Yue, H., Li, S., Chiang, I.-K., Shi, J., Benkovic, S.J., Huang, T.J., 2012. On-chip manipulation of single microparticles, cells, and organisms using surface acoustic waves. Proc. Natl. Acad. Sci. 109, 11105-11109. 
https://doi.org/10.1073/pnas.1209288109

Dong, R., Hu, Y., Wu, Y., Gao, W., Ren, B., Wang, Q., Cai, Y., 2017. Visible-light-driven BiOI-based janus micromotor in pure water. J. Am. Chem. Soc. 139, 1722-1725.

https://doi.org/10.1021/jacs.6b09863

Dong, R., Zhang, Q., Gao, W., Pei, A., Ren, B., 2016. Highly efficient light-driven TiO2-Au Janus Micromotors. ACS Nano 10, 839-844. https://doi.org/10.1021/acsnano.5b05940

Duan, W., Wang, W., Das, S., Yadav, V., Mallouk, T.E., Sen, A., 2015. Synthetic Nano- and Micromachines in Analytical Chemistry: Sensing, Migration, Capture, Delivery, and Separation. Annu. Rev. Anal. Chem. 8, 311-333. https://doi.org/10.1146/annurevanchem-071114-040125

Esteban-Fernández De Ávila, B., Angell, C., Soto, F., Lopez-Ramirez, M.A., Báez, D.F., Xie, S., Wang, J., Chen, Y., 2016. Acoustically Propelled Nanomotors for Intracellular siRNA Delivery. ACS Nano 10, 4997-5005. https://doi.org/10.1021/acsnano.6b01415

Esteban-Fernández de Ávila, B., Angsantikul, P., Li, J., Gao, W., Zhang, L., Wang, J., 2018. Micromotors Go In Vivo: From Test Tubes to Live Animals. Adv. Funct. Mater. 28, 1-12. https://doi.org/10.1002/adfm.201705640

Esteban-Fernández De Ávila, B., Gao, W., Karshalev, E., Zhang, L., Wang, J., 2018. Cell-Like Micromotors. Acc. Chem. Res. 51, 1901-1910. https://doi.org/10.1021/acs.accounts.8b00202

Felfoul, O., Mohammadi, M., Gaboury, L., Martel, S., 2011. Tumor targeting by computer controlled guidance of magnetotactic bacteria acting like autonomous microrobots, in: IEEE International Conference on Intelligent Robots and Systems. IEEE, pp. 1304-1308. https://doi.org/10.1109/IROS.2011.6048668

Felfoul, O., Mohammadi, M., Taherkhani, S., De Lanauze, D., Zhong Xu, Y., Loghin, D., Essa, S., Jancik, S., Houle, D., Lafleur, M., Gaboury, L., Tabrizian, M., Kaou, N., Atkin, M., Vuong, T., Batist, G., Beauchemin, N., Radzioch, D., Martel, S., 2016. Magneto-aerotactic bacteria deliver drug-containing nanoliposomes to tumour hypoxic regions. Nat. Nanotechnol. 11, 941-947. https://doi.org/10.1038/nnano.2016.137

Fernandes, R., Zuniga, M., Sassine, F.R., Karakoy, M., Gracias, D.H., 2011. Enabling cargocarrying bacteria via surface attachment and triggered release. Small 7, 588-592. https://doi.org/10.1002/smll.201002036

Feynman, R.P., 1992. There's plenty of room at the bottom [data storage]. J. Microelectromechanical Syst. 1, 60-66. https://doi.org/10.1109/84.128057

Fournier-Bidoz, S., Arsenault, A.C., Manners, I., Ozin, G.A., 2005. Synthetic self-propelled nanorotors. Chem. Commun. 0, 441-443. https://doi.org/10.1039/b414896g

Gao, W., de Ávila, B.E.F., Zhang, L., Wang, J., 2018. Targeting and isolation of cancer cells using micro/nanomotors. Adv. Drug Deliv. Rev. 125, 94-101. https://doi.org/10.1016/j.addr.2017.09.002

Gao, W., Dong, R., Thamphiwatana, S., Li, J., Gao, W., Zhang, L., Wang, J., 2015. Artificial micromotors in the mouse's stomach: A step toward in vivo use of synthetic motors. ACS Nano 9, 117-123. https://doi.org/10.1021/nn507097k

Gao, W., Pei, A., Wang, J., 2012a. Water-driven micromotors. ACS Nano 6, 8432-8438. https://doi.org/10.1021/nn303309z

Gao, W., Sattayasamitsathit, S., Orozco, J., Wang, J., 2011. Highly efficient catalytic microengines: Template electrosynthesis of polyaniline/platinum microtubes. J. Am. Chem. Soc. 133, 11862-11864. https://doi.org/10.1021/ja203773g

Gao, W., Sattayasamitsathit, S., Uygun, A., Pei, A., Ponedal, A., Wang, J., 2012b. Polymer-based tubular microbots: Role of composition and preparation. Nanoscale 4, 2447-2453. https://doi.org/10.1039/c2nr30138e 
Gao, W., Uygun, A., Wang, J., 2012c. Hydrogen-bubble-propelled zinc-based microrockets in strongly acidic media. J. Am. Chem. Soc. 134, 897-900. https://doi.org/10.1021/ja210874s

Gao, W., Wang, J., 2014. Synthetic micro/nanomotors in drug delivery. Nanoscale 6, 1048610494. https://doi.org/10.1039/c4nr03124e

Garcia-Gradilla, V., Orozco, J., Sattayasamitsathit, S., Soto, F., Kuralay, F., Pourazary, A., Katzenberg, A., Gao, W., Shen, Y., Wang, J., 2013. Functionalized ultrasound-propelled magnetically guided nanomotors: Toward practical biomedical applications. ACS Nano 7, 9232-9240. https://doi.org/10.1021/nn403851v

Ghost, A., Fischer, P., 2009. Controlled propulsion of artificial magnetic nanostructured propellers. Nano Lett. 9, 2243-2245. https://doi.org/10.1021/nl900186w

Goldberg, S.P., Karalis, D.G., Ross, J.J., Chandrasekaran, K., 1993. Severe right ventricular contusion mimicking cardiac tamponade: The value of transesophageal echocardiography in blunt chest trauma. Ann. Emerg. Med. 22, 745-747.

https://doi.org/10.1002/smll.201502391

Guix, M., Meyer, A.K., Koch, B., Schmidt, O.G., 2016. Carbonate-based Janus micromotors moving in ultra-light acidic environment generated by HeLa cells in situ. Sci. Rep. 6, 21701. https://doi.org/10.1038/srep21701

Halder, A., Godoy-Gallardo, M., Ashley, J., Feng, X., Zhou, T., Hosta-Rigau, L., Sun, Y., 2018. Onepot Green Synthesis of Biocompatible Graphene Quantum Dots and their Cell Uptake Studies. ACS Appl. Bio Mater. acsabm.8b00170. https://doi.org/10.1021/acsabm.8b00170

Halder, A., Zhang, M., Chi, Q., 2017. Electroactive and biocompatible functionalization of graphene for the development of biosensing platforms. Biosens. Bioelectron. 87, 764-771. https://doi.org/10.1016/j.bios.2016.09.030

Halder, A., Zhang, M., Chi, Q., 2016. Graphene-Metal Oxide Hybrid Nanostructured Materials for Electrocatalytic Sensing and Sustainable Energy Storage. Rev. Adv. Sci. Eng. https://doi.org/10.1166/rase.2016.1107

Han, X., Wang, C., Liu, Z., 2018. Red Blood Cells as Smart Delivery Systems. Bioconjug. Chem. 29, 852-860. https://doi.org/10.1021/acs.bioconjchem.7b00758

Hong, Y., Diaz, M., Córdova-Fteueroa, U.M., Sen, A., 2010. Light-driven titanium-dioxide-based reversible microfireworks and micromotor/micropump systems. Adv. Funct. Mater. 20, 1568-1576. https://doi.org/10.1002/adfm.201000063

Hoop, M., Mushtaq, F., Hurter, C., Chen, X.Z., Nelson, B.J., Pané, S., 2016. A smart multifunctional drug delivery nanoplatform for targeting cancer cells. Nanoscale 8, 12723-12728. https://doi.org/10.1039/c6nr02228f

Hortelão, A.C., Patiño, T., Perez-Jiménez, A., Blanco, À., Sánchez, S., 2018. Enzyme-Powered Nanobots Enhance Anticancer Drug Delivery. Adv. Funct. Mater. 28, 1-10. https://doi.org/10.1002/adfm.201705086

Hosseinidoust, Z., Mostaghaci, B., Yasa, O., Park, B.W., Singh, A.V., Sitti, M., 2016. Bioengineered and biohybrid bacteria-based systems for drug delivery. Adv. Drug Deliv. Rev. 106, 27-44. https://doi.org/10.1016/j.addr.2016.09.007

Hu, C., Pané, S., Nelson, B.J., 2018. Soft Micro- and Nanorobotics. Annu. Rev. Control. Robot. Auton. Syst. 1, 53-75. https://doi.org/10.1146/annurev-control-060117-104947

Hu, W., Lum, G.Z., Mastrangeli, M., Sitti, M., 2018. Small-scale soft-bodied robot with multimodal locomotion. Nature 554, 81-85. https://doi.org/10.1038/nature25443

Huang, T.Y., Sakar, M.S., Mao, A., Petruska, A.J., Qiu, F., Chen, X.B., Kennedy, S., Mooney, D., Nelson, B.J., 2015. 3D Printed Microtransporters: Compound Micromachines for Spatiotemporally Controlled Delivery of Therapeutic Agents. Adv. Mater. 27, 6644-6650. https://doi.org/10.1002/adma.201503095 
Ibele, M., Mallouk, T.E., Sen, A., 2009. Schooling behavior of light-powered autonomous micromotors in water. Angew. Chemie - Int. Ed. 48, 3308-3312. https://doi.org/10.1002/anie.200804704

Illien, P., Golestanian, R., Sen, A., 2017. "Fuelled" motion: Phoretic motility and collective behaviour of active colloids. Chem. Soc. Rev. 46, 5508-5518. https://doi.org/10.1039/c7cs00087a

Jiang, H.R., Yoshinaga, N., Sano, M., 2010. Active motion of a Janus particle by selfthermophoresis in a defocused laser beam. Phys. Rev. Lett. 105, 268302. https://doi.org/10.1103/PhysRevLett.105.268302

Kagan, D., Benchimol, M.J., Claussen, J.C., Chuluun-Erdene, E., Esener, S., Wang, J., 2012. Acoustic droplet vaporization and propulsion of perfluorocarbon-loaded microbullets for targeted tissue penetration and deformation. Angew. Chemie - Int. Ed. 51, 7519-7522. https://doi.org/10.1002/anie.201201902

Karshalev, E., Esteban-Fernández De Ávila, B., Beltrán-Gastélum, M., Angsantikul, P., Tang, S., Mundaca-Uribe, R., Zhang, F., Zhao, J., Zhang, L., Wang, J., 2018a. Micromotor pills as a dynamic oral delivery platform. ACS Nano 12, 8397-8405. https://doi.org/10.1021/acsnano.8b03760

Karshalev, E., Esteban-Fernández De Ávila, B., Wang, J., 2018b. Micromotors for "chemistry-onthe-Fly." J. Am. Chem. Soc. 140, 3810-3820. https://doi.org/10.1021/jacs.8b00088

Khezri, B., Beladi Mousavi, S.M., Krejčová, L., Heger, Z., Sofer, Z., Pumera, M., 2019. Ultrafast Electrochemical Trigger Drug Delivery Mechanism for Nanographene Micromachines. Adv. Funct. Mater. 29, 1-10. https://doi.org/10.1002/adfm.201806696

Kim, K., Guo, J., Liang, Z., Fan, D., 2018. Artificial Micro/Nanomachines for Bioapplications: Biochemical Delivery and Diagnostic Sensing. Adv. Funct. Mater. 28, 1-19. https://doi.org/10.1002/adfm.201705867

Kostarelos, K., 2010. Editorial: Nanorobots for medicine: How close are we? Nanomedicine 5, 341-342. https://doi.org/10.2217/nnm.10.19

Li, J., Angsantikul, P., Liu, W., Esteban-Fernández de Ávila, B., Thamphiwatana, S., Xu, M., Sandraz, E., Wang, X., Delezuk, J., Gao, W., Zhang, L., Wang, J., 2017a. Micromotors Spontaneously Neutralize Gastric Acid for pH-Responsive Payload Release. Angew. Chemie - Int. Ed. 56, 2156-2161. https://doi.org/10.1002/anie.201611774

Li, J., Ávila, B.E.F. De, Gao, W., Zhang, L., Wang, J., 2017b. Micro/nanorobots for Biomedicine: Delivery, surgery, sensing, and detoxification. Sci. Robot. 2, eaam6431. https://doi.org/10.1126/scirobotics.aam6431

Li, J., Rozen, I., Wang, J., 2016a. Rocket Science at the Nanoscale. ACS Nano 10, 5619-5634. https://doi.org/10.1021/acsnano.6b02518

Li, J., Thamphiwatana, S., Liu, W., Esteban-Fernández De Ávila, B., Angsantikul, P., Sandraz, E., Wang, J., Xu, T., Soto, F., Ramez, V., Wang, X., Gao, W., Zhang, L., Wang, J., 2016b. Enteric Micromotor Can Selectively Position and Spontaneously Propel in the Gastrointestinal Tract. ACS Nano 10, 9536-9542. https://doi.org/10.1021/acsnano.6b04795

Li, T., Li, J., Zhang, H., Chang, X., Song, W., Hu, Y., Shao, G., Sandraz, E., Zhang, G., Li, L., Wang, J., 2016. Magnetically Propelled Fish-Like Nanoswimmers. Small 12, 6098-6105. https://doi.org/10.1002/smll.201601846

Lin, X., Wu, Z., Wu, Y., Xuan, M., He, Q., 2016. Self-Propelled Micro-/Nanomotors Based on Controlled Assembled Architectures. Adv. Mater. 28, 1060-1072. https://doi.org/10.1002/adma.201502583

Ma, X., Hortelao, A.C., Miguel-López, A., Sánchez, S., 2016a. Bubble-Free Propulsion of Ultrasmall Tubular Nanojets Powered by Biocatalytic Reactions. J. Am. Chem. Soc. 138, 13782-13785. https://doi.org/10.1021/jacs.6b06857 
Ma, X., Hortelão, A.C., Patiño, T., Sánchez, S., 2016b. Enzyme Catalysis to Power

Micro/Nanomachines. ACS Nano 10, 9111-9122.

https://doi.org/10.1021/acsnano.6b04108

Ma, X., Jannasch, A., Albrecht, U.R., Hahn, K., Miguel-López, A., Schäffer, E., Sánchez, S., 2015.

Enzyme-Powered Hollow Mesoporous Janus Nanomotors. Nano Lett. 15, 7043-7050. https://doi.org/10.1021/acs.nanolett.5b03100

Ma, X., Sánchez, S., 2017. Bio-catalytic mesoporous Janus nano-motors powered by catalase enzyme. Tetrahedron 73, 4883-4886. https://doi.org/10.1016/j.tet.2017.06.048

Ma, X., Wang, X., Hahn, K., Sánchez, S., 2016c. Motion Control of Urea-Powered Biocompatible Hollow Microcapsules. ACS Nano 10, 3597-3605.

https://doi.org/10.1021/acsnano.5b08067

Magdanz, V., Medina-Sánchez, M., Schwarz, L., Xu, H., Elgeti, J., Schmidt, O.G., 2017. Spermatozoa as Functional Components of Robotic Microswimmers. Adv. Mater. 29, 1606301. https://doi.org/10.1002/adma.201606301

Majumdar, D.P., Stern, J., Tomozawa, Y., 1972. Electromagnetic mass differences. Phys. Lett. B 42, 103-107. https://doi.org/10.1016/0370-2693(72)90728-9

Makhluf, S.B.D., Abu-Mukh, R., Rubinstein, S., Breitbart, H., Gedanken, A., 2008. Modified PVAFe304 nanopartides as protein carriers into sperm cells. Small 4, 1453-1458. https://doi.org/10.1002/smll.200701308

Mallouk, T.E., Sen, A., 2009. Powering nanorobots: Catalytic engines enable tiny swimmers to harness fuel from their environment and overcome the weird physics of the microscopic world. Sci. Am. 300, 72-77. https://doi.org/10.1038/scientificamerican0509-72

Mano, N., Heller, A., 2005. Bioelectrochemical propulsion. J. Am. Chem. Soc. 127, 11574-11575. https://doi.org/10.1021/ja053937e

Medina-Sánchez, M., Schwarz, L., Meyer, A.K., Hebenstreit, F., Schmidt, O.G., 2016. Cellular Cargo Delivery: Toward Assisted Fertilization by Sperm-Carrying Micromotors. Nano Lett. 16, 555-561. https://doi.org/10.1021/acs.nanolett.5b04221

Medina-Sánchez, M., Xu, H., Schmidt, O.G., 2018. Micro- and nano-motors: The new generation of drug carriers. Ther. Deliv. 9, 303-316. https://doi.org/10.4155/tde-2017-0113

Melde, K., Mark, A.G., Qiu, T., Fischer, P., 2016. Holograms for acoustics. Nature 537, 518-522. https://doi.org/10.1038/nature19755

Mitragotri, S., 2005. Healing sound: The use of ultrasound in drug delivery and other therapeutic applications. Nat. Rev. Drug Discov. 4, 255-260. https://doi.org/10.1038/nrd1662

Mohajerani, F., Zhao, X., Somasundar, A., Velegol, D., Sen, A., 2018. A Theory of Enzyme Chemotaxis: From Experiments to Modeling. Biochemistry 57, 6256-6263. https://doi.org/10.1021/acs.biochem.8b00801

Moore, E.G., Grilj, J., Vauthey, E., Ceroni, P., 2013. A comparison of sensitized Ln(iii) emission using pyridine- and pyrazine-2,6-dicarboxylates-part II. Dalt. Trans. 42, 2075-2083. https://doi.org/10.1039/c2dt32229c

Mostaghaci, B., Yasa, O., Zhuang, J., Sitti, M., 2017. Bioadhesive Bacterial Microswimmers for Targeted Drug Delivery in the Urinary and Gastrointestinal Tracts. Adv. Sci. 4, 1-9. https://doi.org/10.1002/advs.201700058

Mou, F., Chen, C., Ma, H., Yin, Y., Wu, Q., Guan, J., 2013. Self-propelled micromotors driven by the magnesium-water reaction and their hemolytic propertiem. Angew. Chemie - Int. Ed. 52, 7208-7212. https://doi.org/10.1002/anie.201300913

Mou, F., Kong, L., Chen, C., Chen, Z., Xu, L., Guan, J., 2016. Light-controlled propulsion, aggregation and separation of water-fuelled TiO2/Pt Janus submicromotors and their "onthe-fly" photocatalytic activities. Nanoscale 8, 4976-4983. 
https://doi.org/10.1039/c5nr06774j

Ornes, S., 2017. Inner Workings: Medical microrobots have potential in surgery, therapy, imaging, and diagnostics. Proc. Natl. Acad. Sci. 114, 12356-12358.

https://doi.org/10.1073/pnas.1716034114

Pantarotto, D., Browne, W.R., Feringa, B.L., 2008. Autonomous propulsion of carbon nanotubes powered by a multienzyme ensemble. Chem. Commun. 0, 1533-1535.

https://doi.org/10.1039/b715310d

Park, B.-W.W., Zhuang, J., Yasa, O., Sitti, M., 2017. Multifunctional Bacteria-Driven

Microswimmers for Targeted Active Drug Delivery. ACS Nano 11, 8910-8923. https://doi.org/10.1021/acsnano.7b03207

Patino, T., Arqué, X., Mestre, R., Palacios, L., Sánchez, S., 2018. Fundamental Aspects of EnzymePowered Micro- and Nanoswimmers. Acc. Chem. Res. 51, 2662-2671. https://doi.org/10.1021/acs.accounts.8b00288

Patiño, T., Feiner-Gracia, N., Arqué, X., Miguel-López, A., Jannasch, A., Stumpp, T., Schäffer, E., Albertazzi, L., Sánchez, S., 2018. Influence of Enzyme Quantity and Distribution on the SelfPropulsion of Non-Janus Urease-Powered Micromotors. J. Am. Chem. Soc. 140, 7896-7903. https://doi.org/10.1021/jacs.8b03460

Peters, C., Ergeneman, O., García, P.D.W., Müller, M., Pané, S., Nelson, B.J., Hierold, C., 2014. Superparamagnetic twist-type actuators with shape-independent magnetic properties and surface functionalization for advanced biomedical applications. Adv. Funct. Mater. 24, 5269-5276. https://doi.org/10.1002/adfm.201400596

Polin, M., Tuval, I., Drescher, K., Gollub, J.P., Goldstein, R.E., 2009. Chlamydomonas swims with two "gears" in a eukaryotic version of run-and-tumble locomotion. Science (80-. ). 325, 487-490. https://doi.org/10.1126/science.1172667

Ren, L., Wang, W., Mallouk, T.E., 2018. Two Forces Are Better than One: Combining Chemical and Acoustic Propulsion for Enhanced Micromotor Functionality. Acc. Chem. Res. 51, 1948-1956. https://doi.org/10.1021/acs.accounts.8b00248

Safdar, M., Khan, S.U., Jänis, J., 2018. Progress toward Catalytic Micro- and Nanomotors for Biomedical and Environmental Applications. Adv. Mater. 30, 1703660. https://doi.org/10.1002/adma.201703660

Safdar, M., Simmchen, J., Jänis, J., 2017. Light-driven micro- and nanomotors for environmental remediation. Environ. Sci. Nano 4, 1602-1616. https://doi.org/10.1039/c7en00367f

Sanchez, S., Ananth, A.N., Fomin, V.M., Viehrig, M., Schmidt, O.G., 2011. Superfast motion of catalytic microjet engines at physiological temperature. J. Am. Chem. Soc. 133, 1486014863. https://doi.org/10.1021/ja205012j

Sanchez, S., Solovev, A.A., Mei, Y., Schmidt, O.G., 2010. Dynamics of biocatalytic microengines mediated by variable friction control. J. Am. Chem. Soc. 132, 13144-13145. https://doi.org/10.1021/ja104362r

Schamel, D., Mark, A.G., Gibbs, J.G., Miksch, C., Morozov, K.I., Leshansky, A.M., Fischer, P., 2014. Nanopropellers and their actuation in complex viscoelastic media. ACS Nano 8, 87948801. https://doi.org/10.1021/nn502360t

Schattling, P., Thingholm, B., Städler, B., 2015. Enhanced Diffusion of Glucose-Fueled Janus Particles. Chem. Mater. 27, 7412-7418. https://doi.org/10.1021/acs.chemmater.5b03303

Schattling, P.S., Ramos-Docampo, M.A., Salgueiriño, V., Städler, B., 2017. Double-Fueled Janus Swimmers with Magnetotactic Behavior. ACS Nano 11, 3973-3983. https://doi.org/10.1021/acsnano.7b00441

Schuerle, S., Soleimany, A.P., Yeh, T., Anand, G.M., Häberli, M., Fleming, H.E., Mirkhani, N., Qiu, F., Hauert, S., Wang, X., Nelson, B.J., Bhatia, S.N., 2019. Synthetic and living micropropellers for convection-enhanced nanoparticle transport. Sci. Adv. 5, eaav4803. 
https://doi.org/10.1126/sciadv.aav4803

Sengupta, S., Dey, K.K., Muddana, H.S., Tabouillot, T., Ibele, M.E., Butler, P.J., Sen, A., 2013.

Enzyme molecules as nanomotors. J. Am. Chem. Soc. 135, 1406-14.

https://doi.org/10.1021/ja3091615

Sengupta, S., Patra, D., Ortiz-Rivera, I., Agrawal, A., Shklyaev, S., Dey, K.K., Córdova-Figueroa, U., Mallouk, T.E., Sen, A., 2014. Self-powered enzyme micropumps. Nat. Chem. 6, 415-422. https://doi.org/10.1038/nchem.1895

Singh, A.V., Hosseinidoust, Z., Park, B.W., Yasa, O., Sitti, M., 2017. Microemulsion-Based Soft Bacteria-Driven Microswimmers for Active Cargo Delivery. ACS Nano 11, 9759-9769. https://doi.org/10.1021/acsnano.7b02082

Singh, A.V., Sitti, M., 2016. Bacteria-Driven Particles: Patterned and Specific Attachment of Bacteria on Biohybrid Bacteria-Driven Microswimmers (Adv. Healthcare Mater. 18/2016). Adv. Healthc. Mater. 5, 2306-2306. https://doi.org/10.1002/adhm.201670097

Sitti, M., 2018. Miniature soft robots - road to the clinic. Nat. Rev. Mater. 3, 74-75. https://doi.org/10.1038/s41578-018-0001-3

Stanton, M.M., Park, B.W., Miguel-López, A., Ma, X., Sitti, M., Sánchez, S., 2017a. Biohybrid Microtube Swimmers Driven by Single Captured Bacteria. Small 13, 1603679. https://doi.org/10.1002/smll.201603679

Stanton, M.M., Park, B.W., Vilela, D., Bente, K., Faivre, D., Sitti, M., Sánchez, S., 2017b. Magnetotactic Bacteria Powered Biohybrids Target E. coli Biofilms. ACS Nano 11, 99689978. https://doi.org/10.1021/acsnano.7b04128

Stoddart, S.J.F., Sauvage, J.-P., Feringa, B.L., 2016. How molecules became machines. Nobel Prize Chem. 2016 50005. https://doi.org/10.4161/cib.23841

Tottori, S., Zhang, L., Qiu, F., Krawczyk, K.K., Franco-Obregõn, A., Nelson, B.J., 2012. Magnetic helical micromachines: Fabrication, controlled swimming, and cargo transport. Adv. Mater. 24, 811-816. https://doi.org/10.1002/adma.201103818

Vartholomeos, P., Fruchard, M., Ferreira, A., Mavroidis, C., 2011. MRI-Guided Nanorobotic Systems for Therapeutic and Diagnostic Applications. Annu. Rev. Biomed. Eng. 13, 157184. https://doi.org/10.1146/annurev-bioeng-071910-124724

Vilela, D., Cossío, U., Parmar, J., Martínez-Villacorta, A.M., Gómez-Vallejo, V., Llop, J., Sánchez, S., 2018. Medical Imaging for the Tracking of Micromotors. ACS Nano 12, 1220-1227. https://doi.org/10.1021/acsnano.7b07220

Volpe, G., Buttinoni, I., Vogt, D., Kümmerer, H.J., Bechinger, C., 2011. Microswimmers in patterned environments. Soft Matter 7, 8810-8815. https://doi.org/10.1039/c1sm05960b

Walker, D., Käsdorf, B.T., Jeong, H.-H.H., Lieleg, O., Fischer, P., 2015. Biomolecules: Enzymatically active biomimetic micropropellers for the penetration of mucin gels. Sci. Adv. 1, e1500501-e1500501. https://doi.org/10.1126/sciadv.1500501

Wang, H., Pumera, M., 2018. Micro/Nanomachines and Living Biosystems: From Simple Interactions to Microcyborgs. Adv. Funct. Mater. 28, 1-17. https://doi.org/10.1002/adfm.201705421

Wang, J., Xiong, Z., Zheng, J., Zhan, X., Tang, J., 2018. Light-Driven Micro/Nanomotor for Promising Biomedical Tools: Principle, Challenge, and Prospect. Acc. Chem. Res. 51, 19571965. https://doi.org/10.1021/acs.accounts.8b00254

Wang, W., Li, S., Mair, L., Ahmed, S., Huang, T.J., Mallouk, T.E., 2014. Acoustic propulsion of nanorod motors inside living cells. Angew. Chemie - Int. Ed. 53, 3201-3204. https://doi.org/10.1002/anie.201309629

Wang, X., Qin, X.H., Hu, C., Terzopoulou, A., Chen, X.Z., Huang, T.Y., Maniura-Weber, K., Pané, S., Nelson, B.J., 2018. 3D Printed Enzymatically Biodegradable Soft Helical Microswimmers. 
Adv. Funct. Mater. 28, 1-8. https://doi.org/10.1002/adfm.201804107

Wong, F., Dey, K.K., Sen, A., 2016. Synthetic Micro/Nanomotors and Pumps: Fabrication and Applications. Annu. Rev. Mater. Res. 46, 407-432. https://doi.org/10.1146/annurevmatsci-070115-032047

Wu, Y., Si, T., Lin, X., He, Q., 2015. Near infrared-modulated propulsion of catalytic Janus polymer multilayer capsule motors. Chem. Commun. 51, 511-514. https://doi.org/10.1039/c4cc07182d

Wu, Y., Si, T., Shao, J., Wu, Z., He, Q., 2016. Near-infrared light-driven Janus capsule motors: Fabrication, propulsion, and simulation. Nano Res. 9, 3747-3756. https://doi.org/10.1007/s12274-016-1245-0

Wu, Z., Esteban-Fernández De Ávila, B., Martín, A., Christianson, C., Gao, W., Thamphiwatana, S.K., Escarpa, A., He, Q., Zhang, L., Wang, J., 2015. RBC micromotors carrying multiple cargos towards potential theranostic applications. Nanoscale 7, 13680-13686. https://doi.org/10.1039/c5nr03730a

Wu, Z., Li, T., Li, J., Gao, W., Xu, T., Christianson, C., Gao, W., Galarnyk, M., He, Q., Zhang, L., Wang, J., 2014. Turning erythrocytes into functional micromotors. ACS Nano 8, 12041-12048. https://doi.org/10.1021/nn506200x

Wu, Z., Lin, X., Si, T., He, Q., 2016. Recent Progress on Bioinspired Self-Propelled Micro/Nanomotors via Controlled Molecular Self-Assembly. Small 12, 3080-3093. https://doi.org/10.1002/smll.201503969

Xu, B., Zhang, B., Wang, L., Huang, G., Mei, Y., 2018. Tubular Micro/Nanomachines: From the Basics to Recent Advances. Adv. Funct. Mater. 28, 1-24. https://doi.org/10.1002/adfm.201705872

Xu, H., Medina-Sánchez, M., Magdanz, V., Schwarz, L., Hebenstreit, F., Schmidt, O.G., 2018. Sperm-Hybrid Micromotor for Targeted Drug Delivery. ACS Nano 12, 327-337. https://doi.org/10.1021/acsnano.7b06398

Xu, L., Mou, F., Gong, H., Luo, M., Guan, J., 2017. Light-driven micro/nanomotors: From fundamentals to applications. Chem. Soc. Rev. 46, 6905-6926. https://doi.org/10.1039/c7cs00516d

Yan, X., Zhou, Q., Vincent, M., Deng, Y., Yu, J., Xu, J., Xu, T., Tang, T., Bian, L., Wang, Y.X.J., Kostarelos, K., Zhang, L., 2017. Multifunctional biohybrid magnetite microrobots for imaging-guided therapy. Sci. Robot. 2, eaaq1155.

https://doi.org/10.1126/scirobotics.aaq1155

Yang, G.-Z., Fischer, P., Nelson, B., 2017. New materials for next-generation robots. Sci. Robot. 2, eaap9294. https://doi.org/10.1126/scirobotics.aap9294

Yang, G.Z., Bellingham, J., Dupont, P.E., Fischer, P., Floridi, L., Full, R., Jacobstein, N., Kumar, V., McNutt, M., Merrifield, R., Nelson, B.J., Scassellati, B., Taddeo, M., Taylor, R., Veloso, M., Wang, Z.L., Wood, R., 2018. The grand challenges of science robotics. Sci. Robot. 3, eaar7650. https://doi.org/10.1126/scirobotics.aar7650

Yasa, O., Erkoc, P., Alapan, Y., Sitti, M., 2018. Microalga-Powered Microswimmers toward Active Cargo Delivery. Adv. Mater. 30, 1804130. https://doi.org/10.1002/adma.201804130

Zhang, H., Duan, W., Lu, M., Zhao, X., Shklyaev, S., Liu, L., Huang, T.J., Sen, A., 2014. Self-powered glucose-responsive micropumps. ACS Nano 8, 8537-8542. https://doi.org/10.1021/nn503170c

Zhang, L., Abbott, J.J., Dong, L., Kratochvil, B.E., Bell, D., Nelson, B.J., 2009. Artificial bacterial flagella: Fabrication and magnetic control. Appl. Phys. Lett. 94, 064107. https://doi.org/10.1063/1.3079655

Zhang, Q., Dong, R., Wu, Y., Gao, W., He, Z., Ren, B., 2017. Light-Driven Au-W03@C Janus Micromotors for Rapid Photodegradation of Dye Pollutants. ACS Appl. Mater. Interfaces 9, 
4674-4683. https://doi.org/10.1021/acsami.6b12081

Zhao, X., Gentile, K., Mohajerani, F., Sen, A., 2018. Powering Motion with Enzymes. Acc. Chem.

Res. 51, 2373-2381. https://doi.org/10.1021/acs.accounts.8b00286

Zhou, D., Li, Y.C., Xu, P., McCool, N.S., Li, L., Wang, W., Mallouk, T.E., 2017. Visible-light controlled catalytic Cu 2 0-Au micromotors. Nanoscale 9, 75-78.

https://doi.org/10.1039/c6nr08088j

TOC

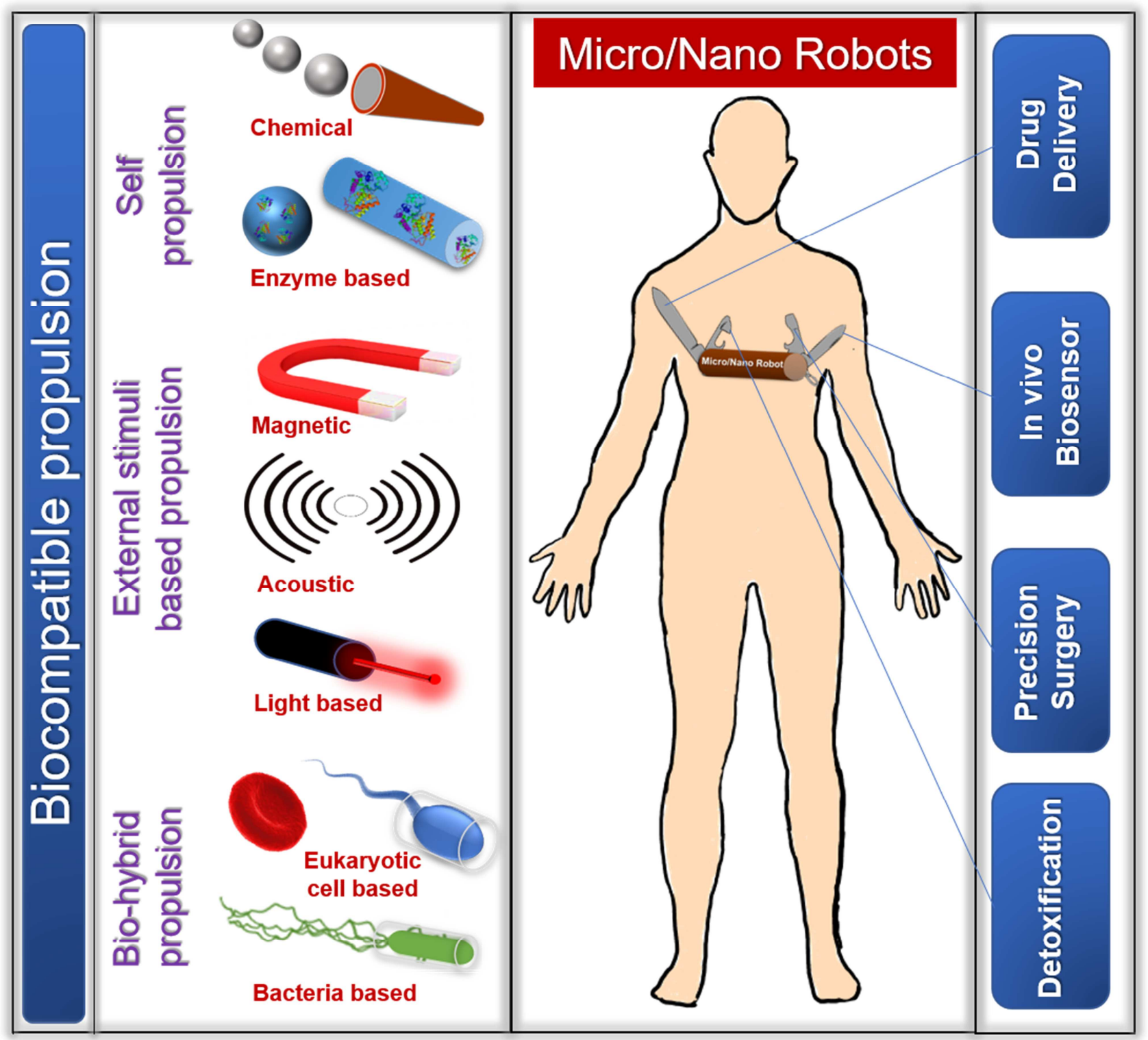



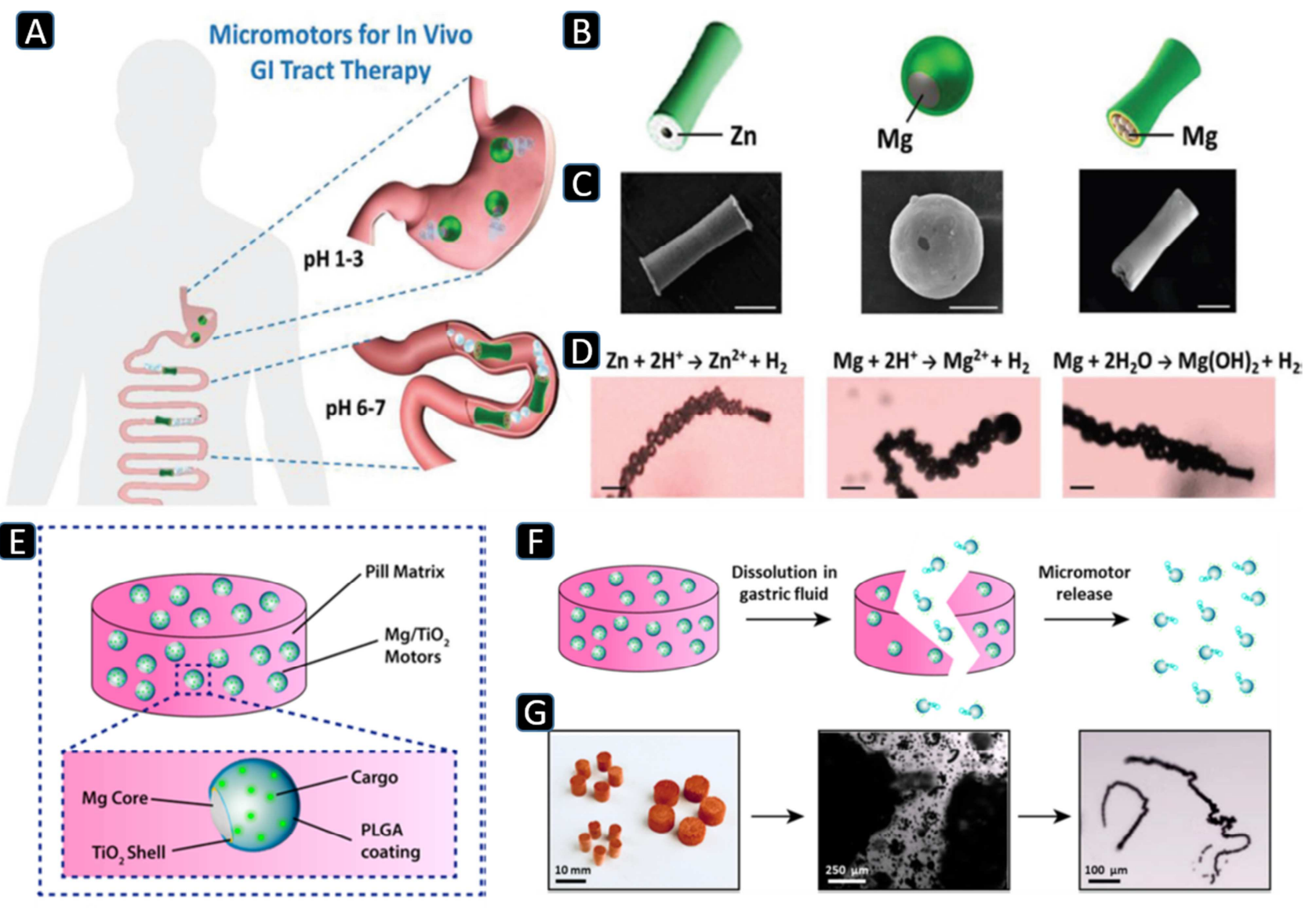

\section{F}
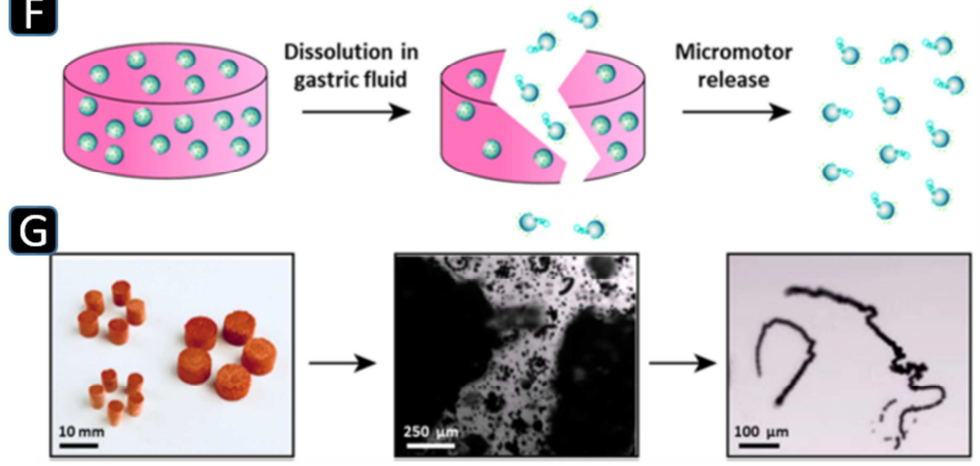

Figure 1. (A) Self/Chemically-propelled MNR for in vivo treatment of GI diseases. (B) Schematic of the three different types of in vivo fuel-propelled micro/nano robot (from left to right): Zn-based tubular micro/nano robots, Mg-based Janus micro/nano robots, and Mg-loaded tubular micro/nano robots. (C) The SEM images of the corresponding micro/nano robots, (Scale bars: 5,10 , and $5 \mu \mathrm{m}$, respectively). (D) Microscopic images showing the propulsion MNRs in simulated gastric acid (left panel and middle panel), and the propulsion of Mg-based tubular micro/nano robots in simulated intestinal fluid (right panel); scale bars: 10, 20, and $10 \mu \mathrm{m}$, respectively. The corresponding chemical reactions are mentioned in the top part of every image. (E) Schematic of the micro/nano robots pill composition containing of a lactose/maltose pill matrix and the encapsulated Mg/TiO2/PLGA MNRs. A zoom-in view shows the micro/nano robot structure with $\mathrm{Mg}$ microsphere core with a TiO2 shell layer and a cargo-loaded PLGA film coating. (F) Schematic of micro/nano robots pill dissolution in gastric fluid with consequent micro/nano robots release. (G) Left: Image showing different sizes of disk-shaped micro/nano robot pills. Center: Microscope image showing the dissolution of a micro/nano robot pill in gastric fluid simulant. Propulsion of the released Mg-based micro/nano robots in gastric fluid simulant. ((A, B) Reproduced with permission(Esteban-Fernández de Ávila et al., 2018) [13] Copyright 2017 WILEYVCH Verlag GmbH \& Co. KGaA, Weinheim) ((C, D), left panel: Reproduced with permission(Gao et al., 2015) Copyright 2014, American Chemical Society; (C, D), middle panel: Reproduced with permission(Li et al., 2017a) Copyright 2017, Wiley-VCH; (C, D), right panel: Reproduced with permission(J. Li et al., 2016b) Copyright 2016, American Chemical Society) ((E, F, G) Reproduced with permission(Karshalev et al., 2018a) Copyright 2018, American Chemical Society). 


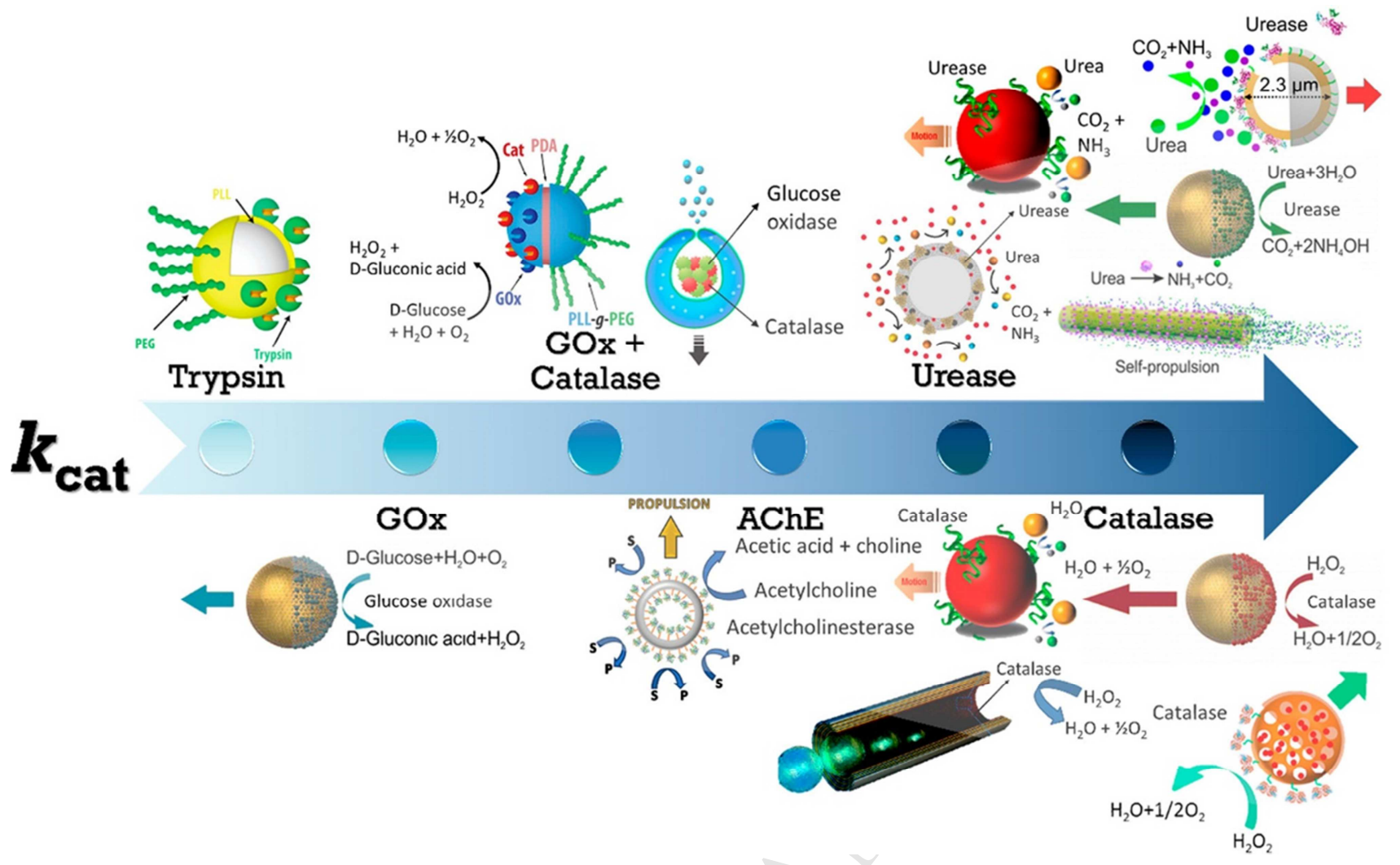

Figure 2. Schematic representation of enzymes used to power micro/nano robots arranged in increasing value of turnover number $\left(\mathrm{k}_{\mathrm{cat}}\right)$ : trypsin(Schattling et al., 2017), glucose oxidase(Ma et al., 2015), $\mathrm{GO}_{\mathrm{x}}$ coupled with catalase(Abdelmohsen et al., 2016; Schattling et al., 2015), acetylcholinesterase (AChE), urease(Hortelão et al., 2018; Ma et al., 2016a, 2016c, 2015), and catalase(Dey et al., 2015; Ma et al., 2015; Ma and Sánchez, 2017; Sanchez et al., 2010). Reproduced/ adapted with permission(Abdelmohsen et al., 2016; Dey et al., 2015; Ma et al., 2016a, 2016c, 2015; Patino et al., 2018; Sanchez et al., 2010; Schattling et al., 2015, 2017) Copyright 2010, 2015, 2016, 2017 and 2018, American Chemical Society. Reproduced with permission(Hortelão et al., 2018) Copyright 2017 WILEY-VCH Verlag GmbH \& Co. KGaA, Weinheim. Reproduced/ adapted with permission from(Ma and Sánchez, 2017) Copyright 2017 Elsevier. 

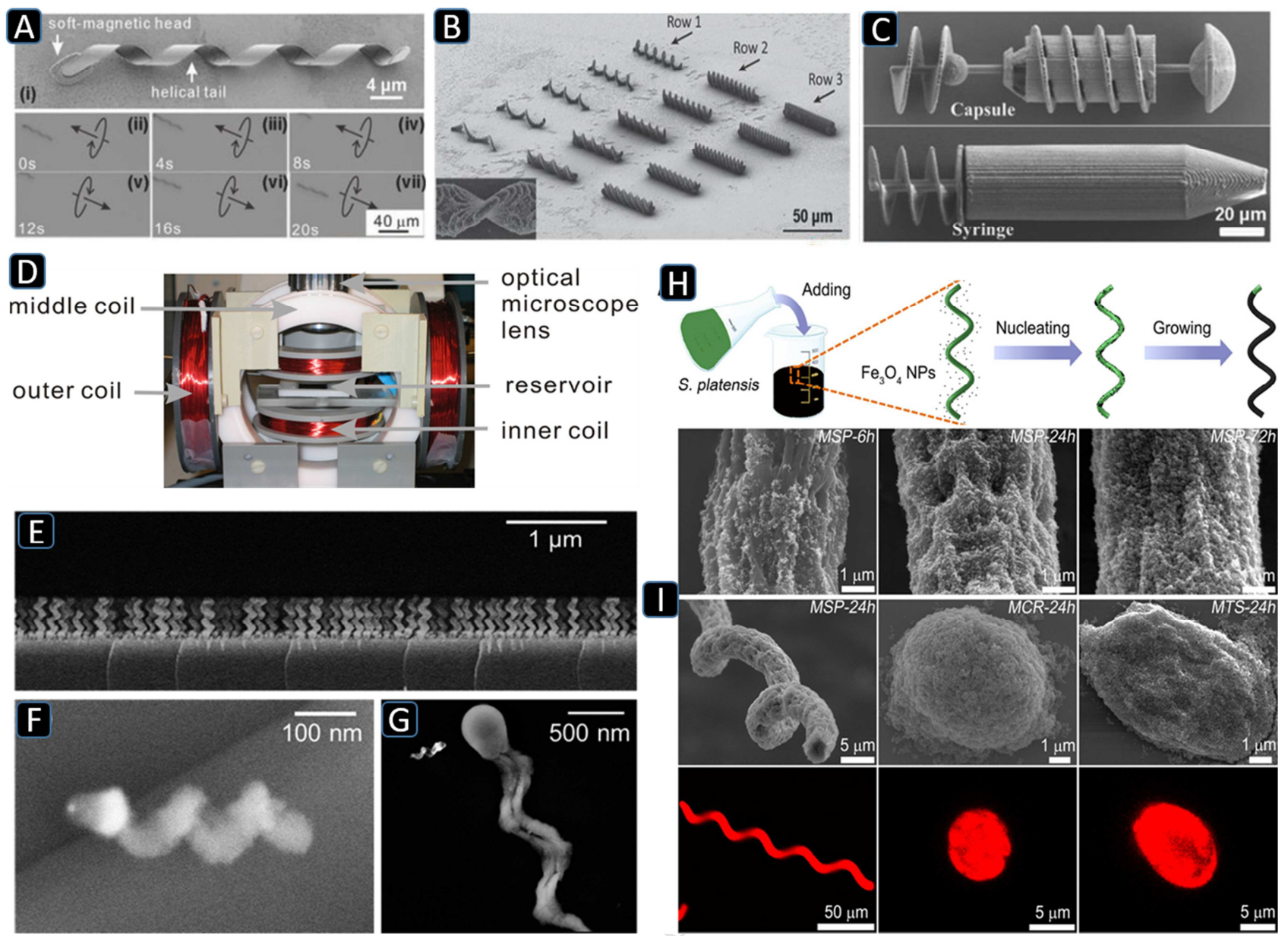

Figure 3. (A) Artificial flagellum based microrobot fabricated from a self-rolled semiconductor. (B) An array of helical structured microrobots fabricated from a nanocomposite of SU-8 and superparamagnetic nanoparticles by direct laser writing (DLW). The inset shows a magnified image of a composite microrobot. (C) Another microcapsule and microsyringe fabricated by DLW. (D) The experimental setup for the swimming tests of ABF using three-axis electromagnetic coils. (E) SEM images of another magnetic nanopropeller based microbot (side view on wafer). (F) Close-up view of one nanohelix based microbot with both the Au-dot and the Ni-section clearly visible; image taken with an SE2 detector. (G) Size comparison between the nano- and the microscrews used as a reference in the work. (H) Schematic of the dip-coating process of Spirulina microalgae in a suspension of $\mathrm{Fe}_{3} \mathrm{O}_{4} \mathrm{NPs}$. Bottom: MSP-6h/24h/72h represent the magnetized Spirulina microalgae subject to $6 / 24 / 72$ hour dip-coating treatments, respectively. As the dipping time increased, the amount of $\mathrm{Fe}_{3} \mathrm{O}_{4} \mathrm{NPs}$, and hence thickness of the $\mathrm{Fe}_{3} \mathrm{O}_{4}$ coating on the Spirulina microalgae, also increased. (I) FESEM (top) and fluorescence images (bottom) of MSP-24h, MCR-24h, and MTS-24h samples. The fluorescence images were taken by a Leica SP8 confocal laser scanning microscope with excitation at $552 \mathrm{~nm}$. ((A, D) Reproduced with permission(Zhang et al., 2009) [69] Copyright 2009, American Institute of Physics. (B) Reproduced with permission(Peters et al., 2014) Copyright 2014, Wiley. (C) Reproduced with permission(Huang et al., 2015) Copyright 2015, Wiley and Copyright 2018, Wiley.) ((E, F, G) Reproduced with permission(Schamel et al., 2014) Copyright 2014, American Chemical Society). ((H, I) Reproduced with permission(Yan et al., 2017) Copyright 2017 American Association for the Advancement of Science (AAS). 


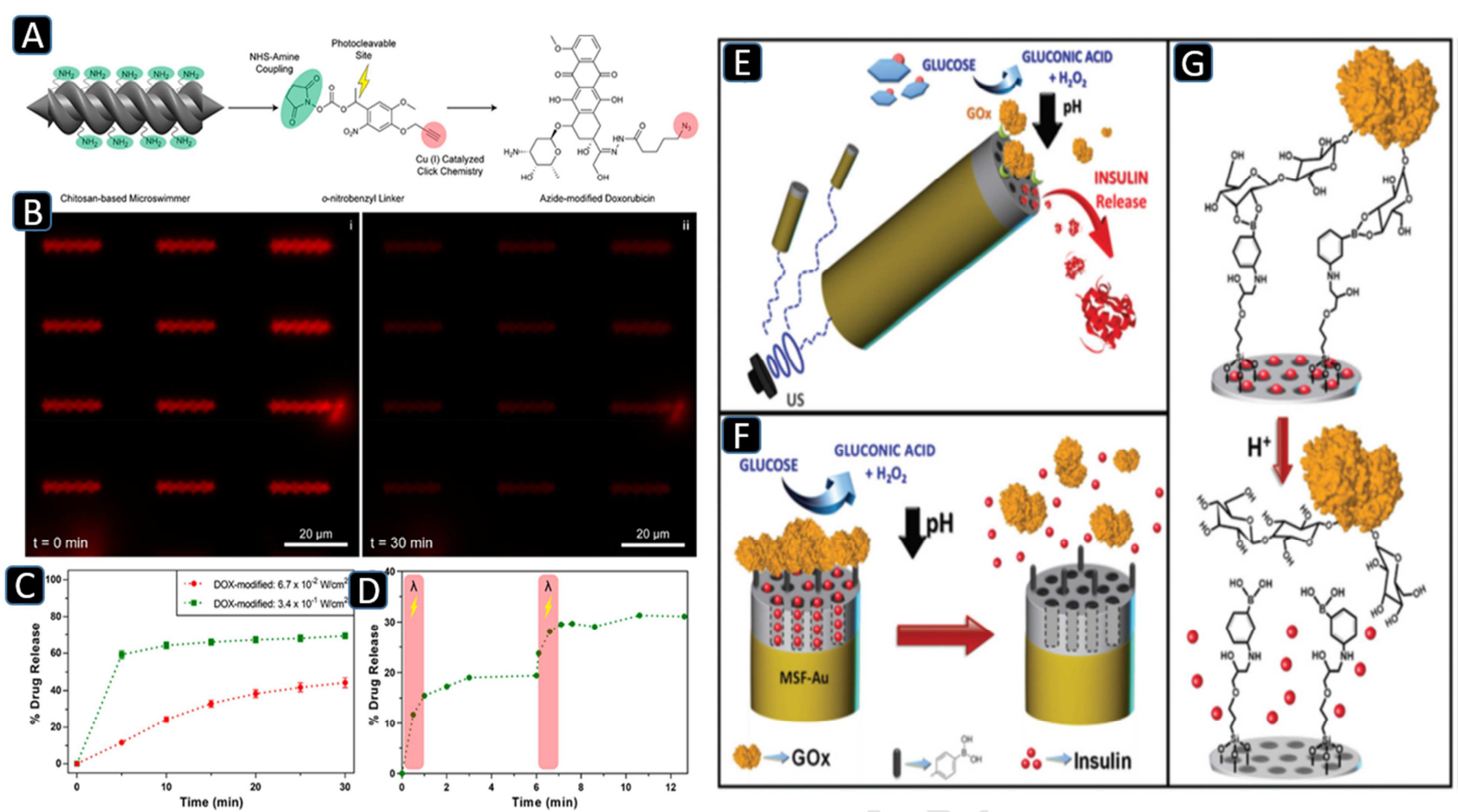

Figure $4(\mathrm{~A})$ Light-triggered drug release from the micro/nano robots. Schematic showing the reaction pathway to obtain DOX-modified micro/nano robots. Amino groups on the micro/nano robots react with the NHS group of onitrobenzyl photocleavable linker molecules. Then, azide-modified DOX reacts with alkyne ends of the micro/nano robots. (B) DOX release from the micro/nano robots exposed to $3.4 \times 10^{-1} \mathrm{~W} / \mathrm{cm}^{2}$ light intensity for $30 \mathrm{~min}$. Decrease in the fluorescence intensity indicates the cleavage of DOX from the micro/nano robots and its release. (C) Cumulative DOX release from the micro/nano robots for $6.7 \times 10^{-2}$ and $3.4 \times 10^{-1} \mathrm{~W} / \mathrm{cm}^{2}$ light intensity. (D) Smart dosing of DOX from the micro/nano robots. A $365 \mathrm{~nm}$ wavelength light is on in the red regions. Approximately 15\% of DOX was released per minute from the micro/nano robots. (E) Schematic illustration showing the $\mathrm{pH}$-triggered insulin release micro/nano robotic approach based on ultrasound-propelled mesoporous silica (MS)-Au nanomotors. (F) Glucose responsive gated insulin containing micro/nano containers. Steps involved in the insulin release mechanism: the PBA functionalized MS segment is capped with $\mathrm{pH}$-sensitive nanovalves based on the GOx gating trigger molecule that leads to the autonomous insulin delivery in the presence of glucose. (G) Protonation of the PBA groups induces the opening of the $\mathrm{pH}$-driven gate and uncapping of the In-loaded nanovalves. ((A, B, C, D) Reproduced with permission(Bozuyuk et al., 2018) Copyright 2018, American Chemical Society) ((E, F, G) Reproduced with permission(Díez et al., 2017) Copyright 2017, Royal Society of Chemistry). 

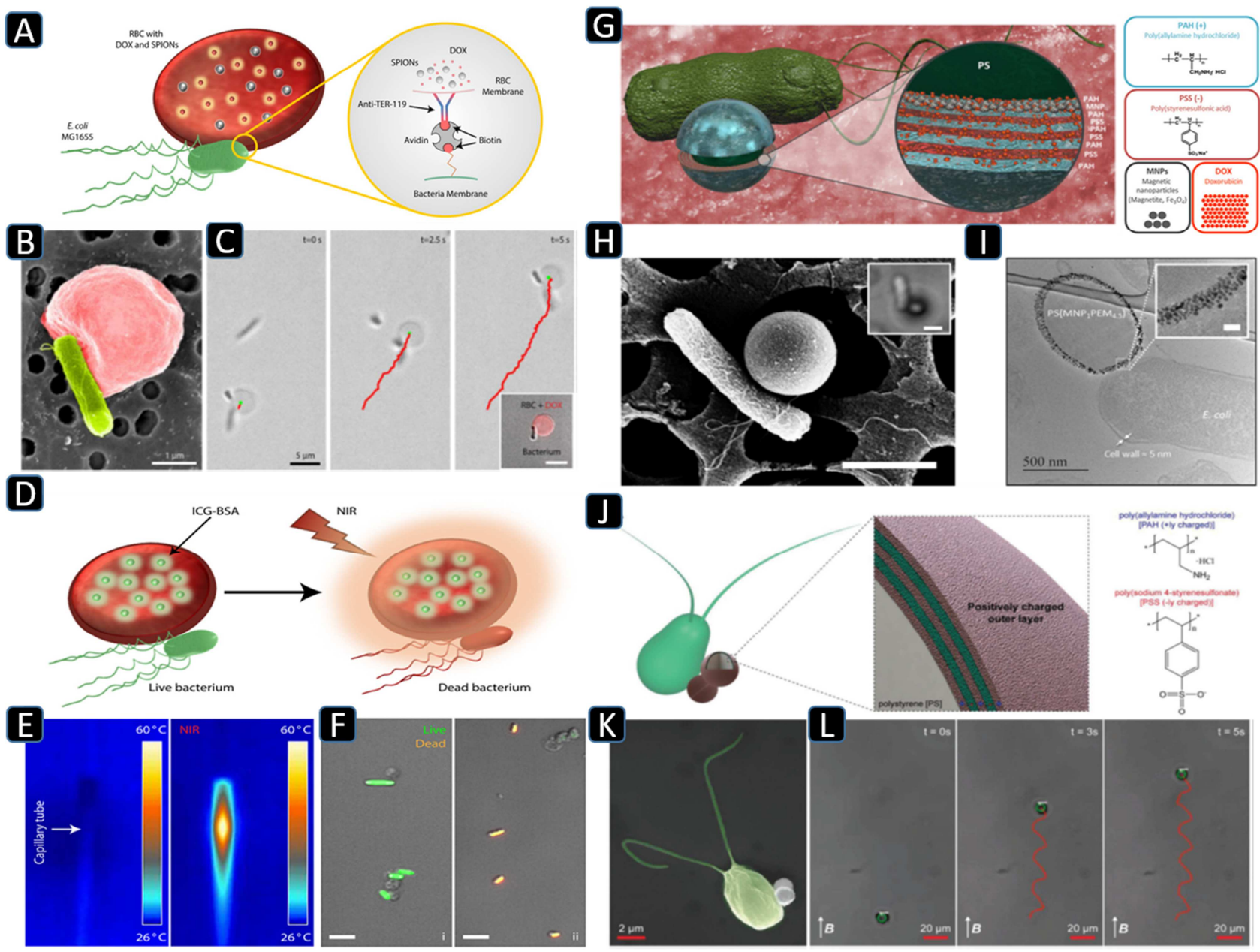

Figure 5 (A) RBC based micro/nano robots (composed of an RBC, loaded with drug molecules and SPIONs, bound to a motile bacterium (bioengineered E. coli MG1655) via biotin-avidin-biotin binding complex) for active cargo delivery. (B) SEM image (pseudocolored red, RBC; pseudocolored green, bacterium) of an example RBC based micro/nano robot with an attached bacterium. (C) 2D propulsion trajectories by RBC based micro/nano robot over time. The inset displays a bacterium attached to an RBC loaded with DOX molecules. Scale bar, $5 \mu \mathrm{m}$. (D) Schematic for on-demand, NIR lighttriggered hyperthermia termination switch for RBC based micro/nano robots. RBC based micro/nano robots, loaded with a photothermal agent (ICG) coupled with BSA, generating heat upon irradiation with NIR and resulting in termination of bacteria. (E) IR thermal images of RBC based micro/nano robots loaded inside a capillary tube before and during NIR irradiation. (F) Live/dead staining of bacteria in RBC based micro/nano robots samples before and after NIR irradiation, respectively. Scale bars, $5 \mu \mathrm{m}$. (G) Schematic overview of the multifunctional bacteria-driven micro/nano robot attached to an E. coli MG1655 bacterium for targeted active drug delivery. PAH, positively charged poly (allylamine hydrochloride); PSS, negatively charged poly(sodium 4-styrenesulfonate); MNPs, magnetic nanoparticles; DOX, doxorubicin, an anticancer drug; PS, $1 \mu \mathrm{m}$ diameter polystyrene micro particle. (H) SEM image of a single micro/nano robot -attached cell (scale bar, $1 \mu \mathrm{m}$ ). The inset in panel is the optical image of a single bacteriadriven micro/nano robot (scale bar, $1 \mu \mathrm{m}$ ). (I) TEM images of thin sections of the microswimmers. The inset in panel I is the TEM image of monolayers of MNRs (scale bar, $50 \mathrm{~nm}$ ). (J) Schematic overview of microalga-powered biohybrid micro/nano robot for active cargo delivery. Synthesized by layer-by-layer polyelectrolyte deposition onto spherical magnetic polystyrene microparticles and through electrostatic interactions between the microalga and the functionalized microparticles. (K) SEM image (pseudocolored green, C. reinhardtii) of an example algal micro/nano robot. (L) Example of 2D propulsion trajectories under $26 \mathrm{mT}$ uniform magnetic field. ((A-F) Reproduced with permission(Alapan et al., 2018a) Copyright 2018, American Association for the Advancement of Science (AAS)); ((G, H, I) Reproduced with permission(Park et al., 2017) Copyright 2017, American Chemical Society) ((J, K, L) Reproduced with permission(Yasa et al., 2018) Copyright 2018, Wiley). 
A

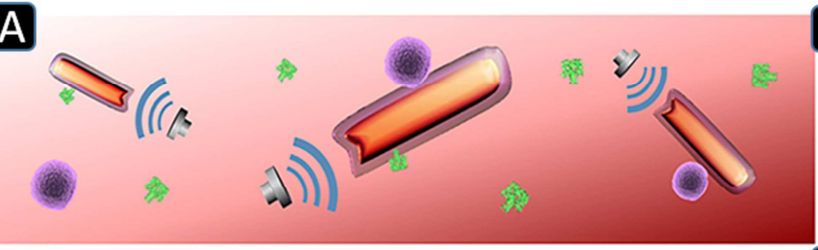

B
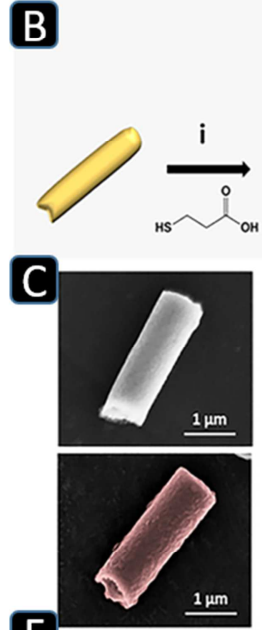

$\mathrm{F}$

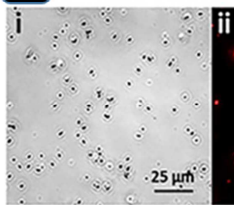

RBC
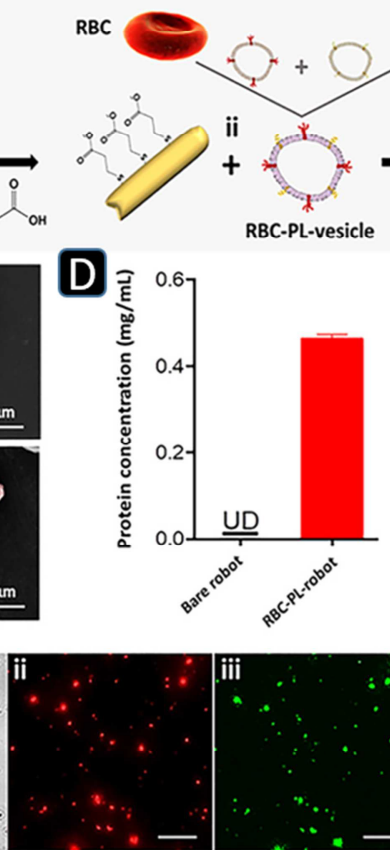
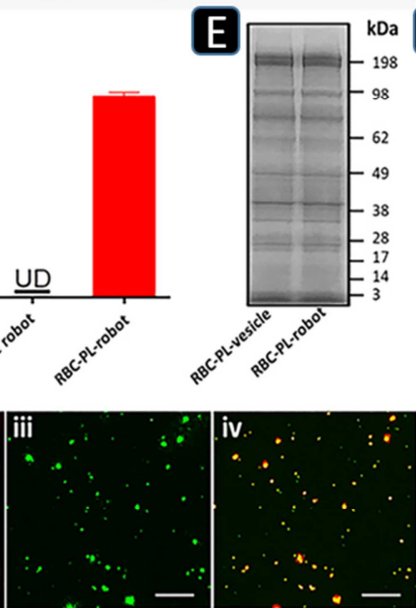
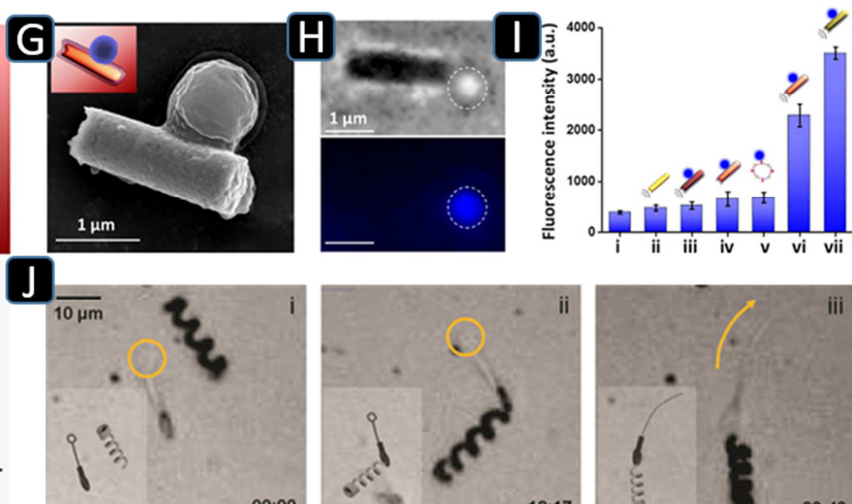

K
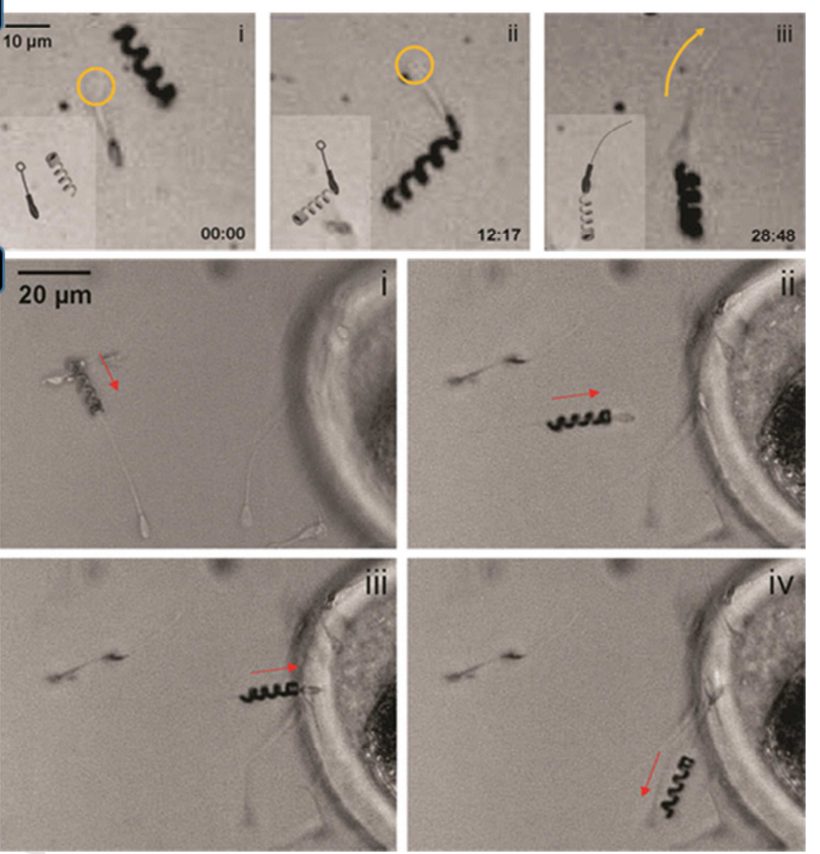

Figure 6. (A) Schematic of biomimetic micro/nano robots for binding and removal of threatening biological agents. (B) Preparation schematic of RBC-PL-robots (C) SEM images of a bare AuNW micro/nano robot without hybrid membrane coating (top) and an RBC-PL-robot (bottom). (D) The measured weight of protein content on bare robots and RBC-PLrobots stored in PBS at $4^{\circ} \mathrm{C}$ for 24 hours. UD, undetectable. (E) SDS-polyacrylamide gel electrophoresis analysis of proteins presents on the RBC-PL-vesicles and the RBC-PL-robots. (F) Optical (i) and fluorescent (ii to iv) images of a group of RBC-PL-robots, in which the RBC membranes were labelled with DiD dye (red) and the PL membranes were labeled with FITC (green). Overlay of the DiD and FITC channels is shown in (iv) (yellow). (G) SEM image of a bacterium attached to an RBC-PL-micro/nano robot. (H) Microscopic images showing the binding of an MRSA USA300 bacterium to an RBC-PL- micro/nano robot: bright-field image (top) and fluorescence image showing the DAPI-stained bacterium (bottom). (I) Normalized fluorescence intensity of DAPI-stained MRSA USA300 bacteria retained on (i) PBS (no robots), (ii) bare robots, (iii) RBC- micro/nano robot (without PL membranes), (iv) RBC-PL- micro/nano robot under a static condition (without US), (v) RBC-PL-vesicles, (vi) Ultrasound-propelled RBC-PL-robots, and (vii) PL-robots (without RBC membranes). (J) Sperm baser micro/nano robot. Sperm pierced by a helix. (i) Helix close to a sperm, (ii) helix approaching and contacting sperm membrane, and (iii) sperm death after being drilled and pierced by a helix. Yellow circle and arrow in (i) and (ii) indicates tail curling due to hypo osmotic swelling and in (iii) swelling recession. Time scale in seconds. (K) Sperm cell coupling (i), transport (ii), approach to the oocyte membrane (iii), and release (iv). ((A-I) Reproduced with permission(De Ávila et al., 2018) Copyright 2018, American Association for the Advancement of Science (AAS)); ((J, K) Reproduced with permission(Medina-Sánchez et al., 2016) Copyright 2015, American Chemical Society). 


\section{Highlights}

This review paper discusses:

- The enormous potential of micro/nano robotics for advancing biomedical applications.

- The latest development of the biocompatible propulsion techniques.

- The future research needed to prompt the widespread adoption of micro/nano robotics in the biomedical sector. 


\section{Declaration of interests}

$\bigotimes$ The authors declare that they have no known competing financial interests or personal relationships that could have appeared to influence the work reported in this paper.

$\square$ The authors declare the following financial interests/personal relationships which may be considered as potential competing interests: 
Arnab Halder wrote the original draft; Yi Sun reviewed and edited. 